\title{
9 Interdependenzen, Gemeinsamkeiten und Unterschiede: Eine Zusammenfassung
}

Nachdem die vier Divisionen getrennt erläutert wurden, sollen in folgenden Kapiteln bestimmte Merkmale, Gemeinsamkeiten und Unterschiede aber auch Interdepenzen zusammenfassend betrachtet werden. Hierzu werden einige der wichtigsten Punkte, die keinen Anspruch auf Vollständigkeit haben, noch einmal aufgegriffen und erläutert.

\subsection{Interdependenzen: Austausch und Zusammenarbeit zwischen den vier südosteuropäischen Divisionen}

Interdependenzen bestanden nicht nur zwischen den muslimischen Divisionen, sondern auch zwischen ihnen und ihrer Schwesterdivision „Prinz Eugen“: ${ }^{1}$ Stammpersonal wurde ausgetauscht, Operationen wurden gemeinsam geplant und durchgeführt. Die Zusammenarbeit der vier südosteuropäischen Waffen-SS-Divisionen „Prinz Eugen“, „Handschar“, „Kama“ und „Skanderbeg“ im „Bandenkampf“ als auch die personelle Fluktuation zwischen ihnen sind daher wichtige Merkmale, um Gemeinsamkeiten, Überschneidungen aber auch Unterschiede nachzuweisen. ${ }^{2}$

Als Hitler im Februar 1943 die Einwilligung zur Aufstellung der „Handschar“ gab, legte Himmler fest, dass Artur Phleps, Kommandeur der Division „Prinz Eugen“ auch für die Organisation und Durchführung der kommenden gemeinsamen Operationen der beiden Divisionen verantwortlich bleiben sollte. Denn diese seien als Fortsetzung bisheriger Operationen im Südostraum zu verstehen. ${ }^{3}$ Dieses Vorgehen zeigte sich auch im ersten Operationszyklus, der noch ganz in den Händen von Phleps lag. ${ }^{4}$ Auch sollte die „Prinz Eugen“ nur in den „benachbarten neuen Raum“ verlegt werden und dadurch in der Nähe der neu aufgestellten muslimischen Division bleiben. ${ }^{5}$

\footnotetext{
1 Selbst Kumm bezeichnet die Divisionen als „Schwesterdivisionen“, was eine gewisse Nähe offenlegt. Vgl. Kumm, Vorwärts Prinz Eugen, S. 273, 335.

2 Vgl. Himmler an SS-Führungshauptamt, SS-Personalhauptamt, SS-Hauptamt, SS-Gruppenführer Phleps und SS-Brigadeführer von Oberkamp, 31.3.1943, BArchB NS19/2601, Bl. 6.

3 Vgl. ebd.

4 Vgl. ebd.

5 Vgl. ebd.
}

Ә Open Access. (c) 2021 Franziska Anna Zaugg, publiziert von De Gruyter. (c) BY lizenziert unter einer Creative Commons Namensnennung 4.0 International Lizenz. https://doi.org/10.1515/9783110730777-009 
Nach der Übergabe des Kommandos der „Prinz Eugen“ an Oberkamp blieb Phleps als Befehlshaber des V. Gebirgskorps auf übergeordneter Ebene für die Koordination der Operationen, die unter Mitwirkung der „Prinz Eugen“ und der „Handschar“ durchgeführt wurden, federführend. Der Partisanenkrieg und die Handhabung der Konzentrationslager in seinem Kommandobereich trugen seine Handschrift: Er war damit beschäftigt, wie er Himmler selbst mitteilte, das Ineinandergreifen und die Verzahnung verschiedener Maßnahmen zu optimieren: „Konzentrationslager, Arbeitskolonnen und die Todesstrafe müssen Hand in Hand die Übeltäter fassen, weil der Balkanmensch die milde Hand nicht verträgt. “6

Die Division „Skanderbeg“ war im Gegensatz zur „Handschar“ und zur „Prinz Eugen“ dem XXI. Gebirgskorps der Wehrmacht unterstellt. Dieses wiederum war Teil der 2. Panzerarmee und somit der Heeresgruppe F. ${ }^{7}$ Trotzdem stand auch sie in Operationen, beispielsweise „Rösselsprung“ oder „Draufgänger“, gemeinsamen mit der „Prinz Eugen“ und der „Handschar“ (Rösselsprung) im Einsatz. Nicht nur zwischen Verbänden der Waffen-SS, sondern auch zwischen Wehrmacht und Waffen-SS wurden Operationen gemeinsam geplant und umgesetzt. ${ }^{8}$ Die Division „Kama“ hingegen wurde nur in den ersten Wochen auf dem Gebiet des NDH, danach aber in Südungarn aufgestellt. Zwar lassen sich auch hier Personalfluktuationen nachweisen, ihr Einsatzradius war jedoch ein anderer. ${ }^{9}$ Wie ein Schreiben Himmlers an Phleps offenlegt, bestand aber der Plan, alle südosteuropäischen Divisionen unter einem Kommando zusammenzuschließen: „Mein Ziel kennen Sie: Die Schaffung zweier zunächst territorialer Korps, eines den bosnischen Raum besetzenden bosnischen Gebirgs-Korps und eines den albanischen Raum besetzenden albanischen Gebirgs-Korps. Dazu kommen die SS-Frw.Geb. Div. ,Prinz Eugen“ sowie die Divisionen des Heeres, für die Abwehr an der Küste und den beweglichen Einsatz gegen hereinbrechende Feindgruppen aus unbefriedeten Gebieten. Diese zwei SS-Gebirgs-Korps und die SS-Frw.Geb.Div. ,Prinz Eugen' als Armeegruppe von insgesamt 5 SS-Gebirgs-Divisionen unter Ihrer Führung und Ihrem Befehl ist das Ziel des Jahres 1944. “10

6 Phleps and Himmler, 10.7.1944, BArchB, NS 19/2154 zitiert nach Schmider, Auf Umwegen zum Vernichtungskrieg?, S. 918.

7 Vgl. Tessin, Verbände, Bd. 4, S. 173.

8 Vgl. Gen. Kdo. XI. Geb. A.K., von Klocke an 297. Inf. Div., 181 Inf. Div., SS-Div. ,Skanderbeg“, 10.7.1944, NARA, T314/664, Bl. 164. „Zusammenfassender Bericht“ Schmidhuber, 2.10.1944, BArchF, RS 3-21/1, Bl. 5.

9 Vgl. Tessin, Verbände, Bd. 4, S. $204 \mathrm{f}$.

10 Vgl. Schreiben Himmler an Phleps, 10.5.1944, BArchB, R9361-III/547576, S. 4. Hier kommt noch einmal die Absicht zum Ausdruck, auch in «Großalbanien» eine zweite Division aufzustellen. 
Die Zusammenarbeit war mitunter auch von Auseinandersetzungen geprägt. Himmler reagierte im Mai 1944 auf Spannungen zwischen Phleps und SS-Sturmbannführer Erich Eberhardt, dem Ia der Division „Prinz Eugen“, auf der einen und dem Stabschef des V. Gebirgskorps, SS-Oberführer Gutsav Krukenberg, auf der anderen Seite, indem er die beiden letzteren versetzte. Außerdem mahnte Himmler Phleps, sein Verhältnis zu Sauberzweig zu verbessern, da er weder auf ihn noch auf Sauberzweig verzichten könne. ${ }^{11}$

\subsubsection{Personalverschiebung von Ost nach Südost}

Bereits am 21. August 1942 schrieb der Chef des Wehrmachtführungsstabs, Alfred Jodl, an Himmler und SS-Obergruppenführer Karl Wolff Folgendes: „Der Führer hat angeordnet, dass die bereits an der Ostfront eingesetzten kroatischen Truppenteile zu einer selbständigen kroatischen Division erweitert werden.“ Mit diesem Schreiben, so Jodl weiter, gebe die Wehrmacht ihr Einverständnis, diese Kroaten, vielfach „Volksdeutsche“, von der Ostfront für die Verwendung in Südosteuropa abzugeben. ${ }^{12}$ Es war dies eine der ersten ganz konkreten Angaben zu einer größeren Truppenverschiebung von Ost- nach Südosteuropa. Auch der ehemalige Major Hermann K. Frank schrieb über die Ostfronterfahrung seiner Einheiten, mit welchen er zuerst im Kosovo, später in Mittelalbanien stationiert war: „Was konnte die alten Russlandkämpfer auch noch erschüttern? Sie waren im Improvisieren Meister geworden.“13

Hinweise, dass Truppen, aber auch Führungspersonal mit Osterfahrung in den Balkan verlegt wurden, sind zahlreich: Beim Rahmenpersonal der südosteuropäischen Divisionen können zahlreiche Versetzungen von der Ostfront nach Südosteuropa nachgewiesen werden. Die bekannteste ist diejenige des Divisionskommandeurs der „Prinz Eugen“ Artur Phleps, der seit 1941 als Offizier im Stab der SS-Division „Wiking“ auch an der Ostfront eingesetzt war. ${ }^{14}$ Ein anschauliches Beispiel bietet SS-Oberführer und Oberst der Polizei Richard Kaaserer, der zuerst als Kommandeur des I./Gebirgs-Jäger-Regiment 2 der „Prinz Eugen“ diente, aufgrund von Misshandlungen seiner Soldaten jedoch versetzt wurde. Darauf war er von Februar bis Frühsommer 1943 im Aufstellungsstab der lettischen

11 Vgl. Schreiben Himmler an Phleps, 10.5.1944, BArchB, R9361-III/547576, S. 1-3.

12 Chef des Oberkommandos der Wehrmacht, Alfred Jodl, an Himmler und SS-Obergruppenführer Karl Wolff, 21.8.1942, BArchB, NS19/319, Bl. 42.

13 Hermann K. Frank: Partisanenkampf in Albanien, in: Allgemeine Schweizerische Militärzeitschrift 120 (1954), S. 356.

14 Vgl. Casagrande, Volksdeutsche SS-Division, S. 189. 
Freiwilligenlegion der Waffen-SS eingesetzt, ${ }^{15}$ bevor er wieder nach Südosteuropa versetzt wurde und dort schließlich die Funktion des SSPF Sandžak übernahm, wobei er eine tragende Rolle bei der Rekrutierung für die „Handschar“ und später für die „Skanderbeg“ spielte. ${ }^{16}$

Auf der unteren Führungsebene ist etwa das Beispiel Günter Borkowskys zu nennen. Im August 1941 war er in der Marschkompanie der Leibstandarte in Prag und zwischen Oktober 1941 bis März 1943 im Fronteinsatz in Russland, unter anderem in Charkow, Kiew und Stalino, wie er zu Protokoll gab. Nach einem Lazarettaufenthalt kam Borkowsky zuerst zur „Prinz Eugen“, danach zur „Handschar“. ${ }^{17}$ Ein ähnliches Beispiel liefert Alfons Zeitler, der bis zum 16. Juni 1943 in der lettischen SS-Freiwilligen-Legion diente, bevor er zur „Prinz Eugen“ versetzt wurde. Dort blieb er bis zum 24. Juni 1944 und wurde an jenem Tag zur „Skanderbeg“" versetzt. ${ }^{18}$

\subsubsection{Personalverschiebung von der „Prinz Eugen“ und lokalen Kräften zu den muslimischen Divisionen}

Bei der Zusammenstellung der Ludwigsburger Behörden zur Aufklärung von nationalsozialistischen Kriegsverbrechen im Zweiten Weltkrieg ist ganz oben auf der Akte B162/20812 zu lesen: „,Div[ision] Handschar‘ zusammengesetzt aus: Volksd[eu]tsch [en], Bosniaken, Slowenen, Albanern, Muselmanen“. ${ }^{19}$ Diese Aufzählung sollte aber nicht darüber hinwegtäuschen, dass genau genommen auch das „reichsdeutsche“ Rahmenpersonal verschiedenen Ethnien angehörte - und sich sowohl aus Deutschen, Österreichern als auch Optanten aus Südtirol zusammensetzte. ${ }^{20}$

Allein die Tatsache, dass die „Handschar“ als Teil des V. SS-Gebirgskorps Artur Phleps, dem ehemaligen Kommandeur der „Prinz Eugen“ unterstellt war, erleichterte den Austausch wie auch Personalverschiebungen zwischen diesen beiden Divisionen. Personalverschiebungen von der „Prinz Eugen“ zu einer der neu aufgestellten muslimischen Divisionen kamen relativ häufig vor, da diese

15 Diese wurde am 10. Februar 1943 aufgestellt.

16 Vgl. SS-Personalakte Richard Kaaserer, geb. 21.8.1896, „Anklageverfügung“, 31.5.1943, BArchB, ehemals BDC, S. 1 .

17 Vgl. Fall Günter Borkowsky USHMM, BArchL, B162/20812.

18 Vgl. SS-Personalakte Alfons Zeitler, BArchB, ehemals BDC. Vgl. auch Kriegsgefangenenbericht, Alfred Schrader, 31.10.1947, VA HEM.OK.BOJCKA, 72A/1a/34, S. 5.

19 Vgl. Fall Günter Borkowsky, USHMM, BArch Ludwigsburg B162/20812, Bl. 43.

20 Vgl. Fall Günter Borkowsky, USHMM, BArch Ludwigsburg B162/20812, Bl. 6. 
Soldaten aufgrund ihrer Kampferfahrung als auch ihrer Mehrsprachigkeit geeignetes Rahmenpersonal für die muslimischen Divisionen darstellten. Zwei der prominentesten Beispiele sind der spätere Divisionskommandeur der „Skanderbeg“, August Schmidhuber, und der spätere Regimentskommandeur in der „Skanderbeg“, SS-Obersturmbannführer Alfred Graf (nach der Neustrukturierung der Division im Oktober 1944). Auch der bereits erwähnte Richard Kaaserer war sowohl bei der „Prinz Eugen“ eingesetzt als auch später in die Aufstellung von „Handschar“ und „Skanderbeg“ involviert. Schmidhuber und Kaaserer kannten sich bereits aus der Zeit in der „Prinz Eugen“.21

Ein weiteres Beispiel liefert Desiderius Hampel, der zuerst in der „Prinz Eugen“ das III./SS-Gebirgs-Jäger-Regiment 13 „Arthur Phleps“ kommandierte, 1943 maßgebend am Aufbau der 13. SS-Gebirgs-Division „Handschar“ beteiligt war und diese von Juni 1944 bis Mai 1945 befehligte. ${ }^{22}$ Aber auch Borkowsky oder Zeitler sind hier zu nennen, die beide von der „Prinz Eugen“ zur „Handschar“ bzw. zur „Skanderbeg“ versetzt wurden. ${ }^{23}$ Oder auch SS-Obersturmführer Georg Floritsch, ein „Volksdeutscher“ aus dem Banat, der in der Division „Handschar“ Bernwalds direkter Vorgesetzter gewesen war und vorher im Rang eines Unterführers in der „Prinz Eugen“ gedient hatte. ${ }^{24}$

Aufgrund des allgemeinen Personalmangels wurde die Abgabe von Personal von der „Prinz Eugen“ zu den anderen südosteuropäischen Divisionen aber nicht gern gesehen, wie die Quellen belegen. Hinsichtlich der sich in Aufstellung befindenden „Handschar“ schrieb Gottlob Berger im August 1943 dem Reichsführer SS, er sei sich durchaus im Klaren darüber, „dass es in der heutigen Zeit schwer ist, nur einen einzigen Mann abzugeben. “25 Problematisch schien ihm aber, dass durch die Weigerung des Divisionskommandeurs von Oberkamp, die Muslime der Division „Prinz Eugen“ abzutreten, sich nun auch die Wehrmacht weigere, ihre muslimischen Soldaten für die Aufstellung einer muslimischen SS-Division freizugeben. Berger nahm den Beauftragten des Reichsführers SS in Kroatien, Konstantin Kammerhofer in Schutz, denn es wäre nicht dessen Schuld, wenn die Aufstellung der „Handschar“ verhindert würde, sondern diejenige von Ober-

21 Vgl. SS-Personalakte Richard Kaaserer, geb. 21.8.1896, „Anklageverfügung“, 31.5.1943, BArchB, ehemals BDC, S. 3.

22 Vgl. Böhm, Die deutschen Volksgruppen, S 405.

23 Vgl. Fall Günter Borkwosky, USHMM, BArchL, B162/20812. Vgl. SS-Personalakte Alfons Zeitler, BArchB, ehemals BDC.

24 Vgl. Bernwald, Muslime, S. 59.

25 Schreiben Berger an Himmler, betr. Muselmanen-Division, 4.8.1943, BArchB, NS19/3504. 
kamps. Berger war sogar der Meinung, dass im Vergleich zur „Handschar“ die „Prinz Eugen“ „bis zum heutigen Tage mit Männern vollgestopft wird“. ${ }^{26}$

Von Oberkamp rechtfertigte sich damit, dass sowohl in der bosnischen Bevölkerung als auch in der „Prinz Eugen“ selbst der Abzug bzw. die Rekrutierung von 4/5 der männlichen muslimischen Bevölkerung in die neu augestellte bosnische SS-Division mit Skepsis aufgenommen würde. Denn dadurch würde „der gesamte muselmanische Raum mit einem Schlage der wehrfähigen Bevölkerung entblößt“. Daraus ergaben sich für ihn weitere Bedenken: Da seine Division große Teile des Raumes sicherte, konnte seiner Meinung nach auf die Muslime in der I./Ustascha-Brigade und dem kroatischen Infanterie-Regiment 9 nicht verzichtet werden. Diese wären sowohl für die Sicherung des Raumes SokolacVlasenica in Ostbosnien als auch zur Sicherung der Eisenbahnlinie von Sarajevo nach Višegrad unabdingbar. Weiter stellte von Oberkamp fest, dass sich „bei der Größe des zu sichernden Raumes und der zahlenmäßig geringen Stärke der vorhandenen deutschen Truppen [...] die SS-Freiw.Geb.-Div. ,Prinz Eugen` der Ansicht der Vertreter der muselmanischen Bevölkerung“ anschließe. ${ }^{27}$ Aus diesem Grund schlug er vor, die befohlenen Abgaben der Muslime, bzw. die Personalverschiebung von der „Prinz Eugen“ zur „Handschar“, nicht auf einen Schlag, sondern Zug um Zug durchzuführen. ${ }^{28}$

Selbst der Polizeigebietsführer Sarajevo, SS-Oberführer Werner Fromm, befand, dass „das Verbleiben muselmanischer Milizkräfte im bosnischen Raum als notwendig erachtet wird“, und zwar solange bis die aufzustellenden Verbände der neuen bosnischen Division in diesen Raum verlegt werden könnten. Von Oberkamp skizzierte das weitere Vorgehen: Seiner Ansicht nach sollte zuerst das erste Gebirgsjäger-Regiment der kroatischen SS-Division aufgestellt und abgewartet werden, bis dieses in den bosnischen Raum verlegt werden konnte. Erst danach sollten weitere Muslime an diese Division abgegeben werden. Wichtig war ihm, dass die muslimische Legion „Hadžiefendić“ als letzte zur Abgabe herangezogen würde, da diese für die Sicherung des Raumes besonders wichtig war. $^{29}$ Ende Juli 1943 weigerte sich außerdem auch das III. Kroatische KorpsKommando, die bei ihnen eingesetzten Muslime an die neu aufzustellende Division abzugeben. ${ }^{30}$

26 Vgl. Schreiben Berger an Himmler, betr. Muselmanen-Division, 4.8.1943, BArchB, NS19/ 3504.

27 Notiz Kommandeur SS-Freiw.Geb.Div. „Prinz Eugen“ von Oberkamp, Ia Tgb.Nr. 196/43 g Kdos., BArchB, NS19/3504, Bl. 34.

28 Vgl. ebd.

29 Ebd.

30 Vgl. Funkspruch Kammerhofer an von Obwurzer, 27.7.1943, BArchB, NS19/3504, Bl. 36. 
Eine breit angelegte Abgabe aller Muslime in die neue muslimische Division „Handschar“ konnte zu diesem Zeitpunkt nicht erreicht werden und im August 1943 meldete Kammerhofer Berger, dass gerade durch die Nicht-Kooperation von Oberkamps die Aufstellung der „Muselmanen-Division“ als vorerst gescheitert zu bezeichnen sei. ${ }^{31}$ Sowohl auf Seiten der Wehrmacht als auch der Waffen-SS kam hinzu, dass

die militärische Lage [...] zweifellos mit Rücksicht auf die Haltung der Italiener in Kroatien als sehr gespannt zu bezeichnen [war] und [...] unbedingt eine Entscheidung des Wehrmachtsführungsstabes erfolgen [musste], ob der Oberbefehlshaber Südost, bezw. der Befehlshaber der deutschen Truppen in Kroatien die Muselmanen aus den kroatischen Einheiten abzugeben hat oder nicht. ${ }^{32}$

Trotzdem war für Kammerhofer klar, dass es nicht anging, dass ausgerechnet die „Prinz Eugen“ sich dem Befehl des Reichsführers SS zur Unterstützung der Aufstellung einer muslimischen Division mit Personal widersetzen würde. Um die Personalverschiebung dennoch zu gewährleisten, schlug er vor, zumindest der Form halber den Abgabe-Befehl so abzuändern wie von Oberkamp angeregt - und die Abgaben dann schrittweise vorzunehmen. ${ }^{33}$

Auch Teile der lokalen „Hadžiefendić“-Legion wurden, trotz der Warnung Oberkamps, noch im Sommer 1943 als Stammpersonal in die Division „Handschar“ eingegliedert, was eine Schwächung der Legion und somit auch der Verteidigung der Region Nordostbosniens für die muslimische Bevölkerung zur Folge hatte. Ein Jahr später spielte sich ein ähnliches Szenario ab, als es um die Abgabe von Personal aus der „Prinz Eugen“ und der „Handschar“ an die „Skanderbeg“ ging. Doch auch in diesem Fall erfolgte zumindest eine teilweise Abgabe von Personal aus den beiden bereits bestehenden Divisionen: So wurden beispielsweise unter SS-Brigadeführer Otto Kumm, seit dem 30. Januar 1944 Divisionskommandeur der „Prinz Eugen“, weitere „Volksdeutsche“ nach Mitrovica versetzt, um dort bei der geplanten Rekrutierung einer albanischen Division einen „harten Kern“ zu bilden. ${ }^{34}$

Im Frühjahr 1944, als schließlich die Division „Skanderbeg“ aufgestellt wurde, hatte sich die personelle Situation weiter verschlechtert. Phleps, der als Kommandierender General des gesamten V. SS-Gebirgskorps die personelle Situation im Überblick hatte, stellte fest, dass weder von der bosnischen noch von der Division „Prinz Eugen“ Personal für die „Skanderbeg“ abgezogen werden könnte, denn der

31 Aktenvermerk Kammerhofer an Berger, 3.8.1943, BArchB, NS19/3504, Bl. 39.

32 Ebd.

33 Vgl. ebd., Bl. 40.

34 Vgl. Latruwe/Kostic, Division Skanderbeg, S. 143. 
Anteil an Führern und Unterführern wäre bei der „Prinz Eugen“ auf unter 50 Prozent des Solls gesunken. Letztlich gab es für ihn nur eine Lösung: Deutsche bzw. „Volksdeutsche“ aus dem Reich und dem Südosten, „Vornehmlich aus Siebenbürgen und Ungarn“, zur „Skanderbeg“ zu versetzen. ${ }^{35}$ Dass dennoch Personalverschiebungen von der „Prinz Eugen“ wie auch der „Handschar“ zur „Skanderbeg“ stattfanden, beweist etwa Luthers Vortragsnotiz: Er stellte im Juni 1944 fest, das an die „Skanderbeg“ abgegebene Personal fehle nun bei den beiden anderen Divisionen. ${ }^{36}$

Als die zur „Kampfgruppe“ geschrumpfte „Skanderbeg“ im Januar 1945 in die „Prinz Eugen“ eingeliedert wurde, fand ein letzter größerer Personalaustausch statt und schloß somit den Kreis: Wehrpässe und Stammkarten der Soldaten der „Skanderbeg“ wurden nun den Verantwortlichen der „Prinz Eugen“ überreicht, deren Kommandeur Schmidhuber wurde. ${ }^{37}$

\subsubsection{Personalverschiebungen zwischen den muslimsichen Divisionen}

Die größte Personalverschiebung von der „Handschar“ zur Division „Skanderbeg“ fand im Frühjahr 1944 statt, als sowohl die im albanischen Bataillon des Regiments 28 der „Handschar“ eingesetzten als auch auf andere Einheiten verteilten Albaner als Stammpersonal zur „Skanderbeg“ versetzt wurden. Schrader schreibt hierzu: „Im Mai 1944 begann die Aufstellung der 21. Waffen-Geb[irgs]Div[ision] SS ,Skanderbeg‘ in Albanien. Die Stamm-Mannschaften dazu bildeten ehemalige Angehörige der 13. Div[ision] ,Handschar‘, die aus allen Einheiten dieser Division herausgezogen wurden und in Albanien beheimatet waren [...].“38 Nach Franje Matheis wollte Sauberzweig, wie bereits erwähnt, die Albaner aus der „Handschar“ entfernen, weil diese ohne Befehl Zivilisten ermordet hatten: „Sie wurden aus der Div[ision] entfernt und nach Albanien geschickt, wo sie als Grundlage bei der Schaffung der ,Skenderbeg ' [sic] Division dienten.“39

35 Phleps an Himmler, 7.5.1944, BArchB, NS 19/2601, Bl. 95.

36 Vgl. Vortragsnotiz Luther, 4.6.1944, PAAA, Inland IIg R100696.

37 Vgl. Kampfgruppe SS-Jgt.Rgt. „Skanderbeg“, 13.1.1945, BArchF, RS 3-21/2, Bl. 149.

38 Kriegsgefangenenbericht, Alfred Schrader, 31.10.1947, VA HEM.OK.BOJCKA, 72A/1a/34, S. 2. Viele dieser Albaner stammten aber auch aus dem zu Serbien gehörenden Teil des „Sandžak“.

39 Vernehmungsprotokoll Matheis, Franje, Office of Chief of Council for War Crimes Translation of Document No. NO-4951, Landeskommission der Feststellung der Verbrechen der Okkupatoren und ihrer Helfershelfer, Inv. Nr. 35874, Nachlass Vopersal, BArchF, N 756/169a. 
Aus den Anträgen auf „Angehörigenunterhaltszahlungen“, die in den Archiven Jugolsavije und Prishtina/Priština erhalten sind, lassen sich an einigen Beispielen Versetzungen von der „Handschar“ zur „Skanderbeg“ auch auf unterster Ebene mit Namen und Geburts- bzw. Wohnorten der Betroffenen belegen oder zumindest ableiten, da alle albanischen Divisionsangehörigen im Frühjahr 1944 zur „Skanderbeg“ versetzt wurden. ${ }^{40}$

Auf der Ebene der Unterführer und Führer können in einigen Fällen ebenfalls Namen genannt werden: So etwa Alfred Schrader, der zuerst die 21. Jägerkompanie im IV./Regiment 28 kommandierte; nach Differenzen mit dem Regimentskommandeur aber in Gunja zur Regelung des Nachschubs eingesetzt war. Nach einer Vertretung des Adjutanten des I. Bataillons kam Schrader aufgrund einer Erkrankung ins Lazarett und wurde von dort zuerst wieder nach Gunja und schließlich zum I. Bataillon und somit zur Division „Skanderbeg“ versetzt. ${ }^{41}$ Auch der ehemalige Leiter des Ersatzkommandos Südost, Jakob Hauser, war 1944 zur „Skanderbeg“ versetzt worden und kommandierte dort ab Juni 1944 das GebirgsJäger-Regiment 50 - und nach der Neuaufstellung der Division bzw. ihrer Restrukturierung als Regiment das IV. Bataillon. ${ }^{42}$

Weitere größere Personalverschiebungen fanden von der „Handschar“ zur „Kama“ statt. Erstere musste für jede Abteilung des Artillerieregiments eine Batterie als Personaleinheit abgeben. ${ }^{43}$ Mario Werhas und Božidar Mikulčić erwähnen in ihrer Zusammenstellung 54 Führer, 187 Unterführer und 1.137 Mannschaften, die von der „Handschar“ zur „Kama“ versetzt werden sollten. Alles in allem sollen laut ihren Angaben rund 2.000 von der ersten zur zweiten bosnischen Division versetzt worden sein. ${ }^{44}$

40 Vgl. bspw. Suleiman, Barhin oder Smali, Mustafa, die zuerst für die „Handschar“ rekrutiert, später zur „Skanderbeg“ versetzt wurden. AJ 110, F 697 und F 727. Vgl. weitere die Personalakten von Šečirović, Osman aus Brecë/Breće, 9.7.1943; Seidir, Rifat, Reçica/Rećica, 3.7.1943; Nuha, Imer, Belo Polje, 1.6.1943; Bahtiri, Dzemail, Selo, 29.6.1943, Hasan-Feizov, Muharem, Palatna, 1.6.1943, Kuskić, Lutvo, Potok, 6.9.1943, Arkivi Kosoves, F: dosjete robërve të luftës në Gjermani, V: 1940-1945, K: 1.

41 Vgl. Kriegsgefangenenbericht, Alfred Schrader, 31.10.1947, VA HEM.OK.BOJCKA, 72A/1a/ 34, S. 1 .

42 Vgl. Kriegsgefangenenbericht „Bericht über die 13. SS Division ,Handschar‘, ihre Aufstellung, Gliederung“, Walter Eipel, 14.11.1947, VA, HEM.OK.BOJCKA, 72-A/1-a/32, S. 2. Vgl. Kriegsgefangenenbericht, Alfred Schrader, 31.10.1947, VA HEM.OK.BOJCKA, 72A/1a/34, S. 5. Vgl. Frans Noij, Zusammenstellung der höheren Dienstgrade innerhalb der Division „Skanderbeg“, unveröffentlicht.

43 Vgl. Tessin, Verbände, Bd. 4, S. 205.

44 Vgl. Mario Werhas, Božidar Mikulčić, „Handschar“, „Skanderbeg“, „Kama“,S. 48 f. 
Eine letzte größere Personalverschiebung fand am 26. September 1944 statt: Die in der Division „Kama“ verbliebenen Muslime sollten zur neugegliederten „Handschar“ versetzt werden und diese verstärken..$^{45}$ Darunter befanden sich auch Imame, so etwa Mušan Tunović, der von seiner Ausbildung in Guben zur „Kama“ und danach zur Schwesterdivision kam. ${ }^{46}$ In umgekehrter Richtung sind im Oktober 1944 auch Personalverschiebungen von der „Handschar“ zum „Strafbataillon“, dem 2. SS-Baubataillon „Kama“ belegt; die „Kama“ als Division existierte zu diesem Zeitpunkt bereits nicht mehr. ${ }^{47}$

\subsubsection{Personalverschiebungen von der Wehrmacht zu den Divisionen}

Im Herbst 1944 kam es zu größeren Personalverschiebungen von der Wehrmacht zur „Handschar“ und zur „Skanderbeg“. Beide Divisionen wurden durch zurückkehrende Wehrmachtssoldaten aus Griechenland verstärkt. Bei der „Handschar“ handelte es sich um rund 3.000 Soldaten, die vorher in Kreta stationiert gewesen waren..$^{48}$ Die „Skanderbeg“ wurde durch 3.800 Mann der Marine und anderer Einheiten, die ebenfalls in Griechenland, unter anderem in Kefalonia, stationiert gewesen waren, verstärkt. ${ }^{49}$ Dass diese zwangsversetzten Soldaten der Marine ein sehr gespaltenes Verhältnis zur ihren neuen Divisionen hatten und sich der ausweglosen Situation bewusst waren, zeigt etwa das von ehemaligen Marineangehörigen gedichtete Divisionslied der „Skanderbeg“.:50

1. Kamerad uns ist der Marschbefehl bekannt

Wir müssen weiter ziehen

Verlassen müssen wir dieses Land, dass wir uns wiedersehn

Ja, wenn die roten Rosen blühen und alles ist vorbei

Dann werden wir uns wiedersehn. Leb wohl mein Schatz, ahoi.

2. „Skanderbeg“ ist unser Regiment genannt

Wir marschieren nun zurück

Albanien, Serbien und Kroatisch Land das brach

45 Vgl. Kaltenegger, Totenkopf und Edelweiss, S. 56.

46 Vgl. Bougarel, La division Handschar, S. 182f.

47 Vgl. Lappin-Eppel, Ungarisch-jüdische Zwangsarbeiter, S. 340 f. Vgl. Werhas, Mikulčić, „Handschar”, „Skanderbeg“, „Kama“, S. 49.

48 Vgl. Kaltenegger, Totenkopf und Edelweiss, S. 56.

49 Vgl. Zaugg, Albanische Muslime, S. 273. Vgl. Kriegsgefangenenbericht Heinrich Maus, ohne Datum, VA HEM.OK.BOJCKA, 71/1/19.

50 Vgl. Brief Kurt Kopf an Vopersal, 4.7.1976, BArchF, N756/182a. Zur Aussichtslosigkeit der Situation für das deutsche Personal in Südosteuropa vgl. auch Schmider, Klaus, Der jugoslawische Kriegsschauplatz, S. 1055. 


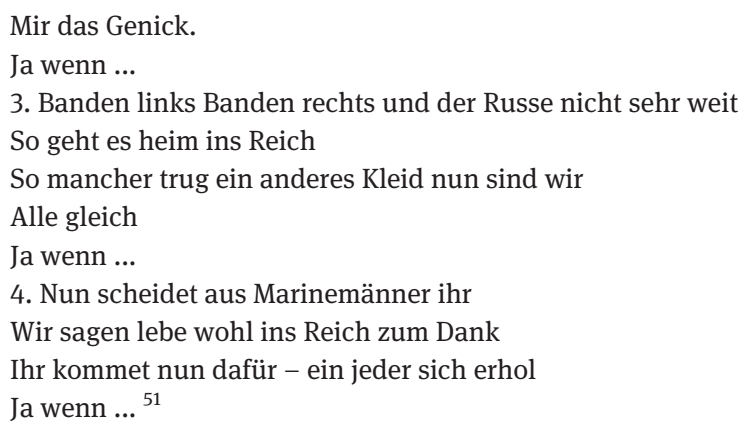

\subsubsection{Kriegsverbrechen: Ausdruck interethnischer lokaler Konflikte oder Weiterführung der KZ- und Ost-Erfahrungen?}

Wie an oben genannten Beispielen gezeigt waren personelle Verflechtungen zwischen den vier hier vorgestellten Divisionen an der Tagesordnung: einerseits durch Personalfluktuation, andererseits durch gemeinsam geplante und durchgeführte Operationen bzw. ganze Operationszyklen. In diesem Kapitel soll der Frage nachgegangen werden, wie sich die Erfahrungen, welche die Soldaten in anderen Divisionen (der „Prinz Eugen“ oder osteuropäischen, beispielsweise der lettischen) gesammelt hatten, auf ihr Verhalten innerhalb der „Handschar“, der "Skanderbeg“ und der „Kama“ und auf den Partisanenkrieg in Südosteuropa auswirkten. Wurde der an der Ostfront neu erfahrene Referenzrahmen auch auf Südosteuropa angewendet - und falls ja, wie? ?2 $^{2}$

Auf der Führungsebene finden sich in den vier südosteuropäischen Divisionen zwei Hauptgruppen, die sich beide durch einschlägige Gewalterfahrungen auszeichneten. Die erste Gruppe hatte solche während ihres Dienstes in Konzentrationslagern gesammelt, die zweite Gruppe war an Gewaltexzessen in Osteuropa beteiligt gewesen oder hatte sie zumindest miterlebt. Hördler weist in seinem Aufsatz zu Interdependenzen zwischen KZ-Personal und Führungspersonal in den einzelnen Divisionen darauf hin, dass „Prinz Eugen“, „Handschar“ und „Kama“

51 Brief Kurt Kopf an Wolfgang Vopersal, 4.7.1976, BArchF, N 756/182a.

52 So stellt sich etwa die Frage, wie die Soldaten ihre Erfahrungen durch Deutungsmuster innerhalb des Referenzrahmens einordneten und wie sie lernten, den Krieg und Verbrechen auch Massenerschießungen - als „Arbeit“ zu betrachten. Einen hohen Stellenwert nehmen im orientierten Referenzrahmen auch Vorschriften, die eigene Position innerhalb einer Hierarchie und der Grad der Vergemeinschaftung der eigenen Person ein. Vgl. Neitzel, Welzer, Soldaten, S. 34-42. 
geradezu Sammelbecken für ehemaliges SS-Lagerpersonal waren. ${ }^{53}$ Bei einigen überschnitten sich die beiden genannten Erfahrungsbereiche: „Auffällig ist die Konzentration von KZ-Führungspersonal in den Divisionen mit volksdeutschen und muslimischen SS-Soldaten, die meist im Partisanenkampf und bei ,Befriedungsaktionen' gegen die Zivilbevölkerung eingesetzt waren“. ${ }^{54}$ Er verweist auch auf zahlreiche SS-Unterführer aus den Kommandostäben der Lager, insbesondere Block- und Rapportführer, die sich direkt an Misshandlungen und Mordaktionen in den Lagern beteiligt hatten. Solche „Vernichtungsspezialisten“ übernahmen nun die Führung der südosteuropäischen Waffen-SS-Divisionen. ${ }^{55}$ Auch Casagrande erwähnt die vorgesehene Versetzung von SS-Hauptsturmführer Bothmann und seiner 85 Mann zur „Prinz Eugen“. Bothmann war mit seinem Sonderkommando zuständig für die Ermordung der jüdischen Bevölkerung im Vernichtungslager Kulmhof bei Łódź. ${ }^{56}$ Dr. Brandt betonte in einem Brief an Kaltenbrunner, dass Bothmann und seine Männer ihre neuen Kameraden in der „Prinz Eugen“ über ihren Einsatz in Polen nicht informieren sollten. ${ }^{57}$ Einen anderen außerordentlichen Fall stellt Viktor Brack dar, der vor seinem Einsatz in Südosteuropa am Euthanasie-Programm, an der Vorbereitung der ersten Gaswageneinsätze in Riga und Minsk sowie am Aufbau der Todeslager und Gaskammern in Polen beteiligt gewesen war. Auf eigenen Wunsch wurde er ab Sommer 1942 im Rang eines SS-Untersturmführers in der Division „Prinz Eugen“ eingesetzt. $^{58}$

Einige Protagonisten innerhalb der südosteuropäischen Divisionen kannten sich bereits von anderen Einsatzorten; so hatte etwa der für die ideologische Schulung der „Handschar“ verantwortliche Ekkehard Wangemann, Leiter der Abteilung VI, vor seinem Einsatz in Südosteuropa in der an der Ostfront eingesetzten flämische Freiwilligenlegion gedient, die $\mathrm{zu}$ diesem Zeitpunkt von SS-Sturmbannführer Joseph Fitzthum geführt wurde, der wiederum seit Dezember 1943 als HSSPF Albanien eingesetzt war. ${ }^{59}$

Einerseits war sicher eine Brutalisierung durch die an der Ostfront und in KZ gemachten Erfahrungen beim deutschen bzw. „volksdeutschen“ Rahmenpersonal mitverantwortlich für die rücksichtslose und gewalttätige Vorgehens-

53 Vgl. Hördler, KZ-System und Waffen-SS, S. 98.

54 Ebd., S. 94.

55 Vgl. ebd., S. 94, 98.

56 Vgl. Casagrande, Volksdeutsche SS-Division, S. $248 \mathrm{f}$.

57 Vgl. ebd. S. 249.

58 Vgl. ebd. S. 216.

59 Vgl. SS-Personalakte Ekkehard Wangemann, „Beförderung“ Rudolf Brandt an SS-Obergruppenführer Schmitt, 9.5.1942, BArchB, ehemals BDC. 
weise im Partisanenkrieg. Andererseits dürften auch ähnliche Erfahrungen von Führern, die vorher in Ustaša-Einheiten gedient hatten, eine Rolle gespielt haben. ${ }^{60}$ Doch dass nicht erst die von der Ostfront kommenden Waffen-SSAngehörigen diesen Referenzrahmen nach Südosteuropa brachten, zeigt auch das Beispiel der Vorgängereinheit der „Handschar“, unter dem Kommando Muhamed Hadžiefendićs. Diese Legion „Hadžiefendić“ plünderte serbische Dörfer und misshandelte oder tötete ihre Bewohner. ${ }^{61}$ So fand also zwischen 1941-1943 parallel zur Brutalisierung von Ostfrontsoldaten eine Gewaltsozialisation Angehöriger verschiedener Milizverbände im NDH statt, die bereits geprägt durch (von Četnik, Ustaša oder selbst begangene) Massaker in die Division „Handschar“ eintraten. Ihre Vorgeschichten mögen zwar die in der „Handschar“ begangenen Massaker, Vergewaltigungen, Folter und auch Verstümmelung von Leichen erklären - sie aber als spontanen Ausdruck „ethnischen Hasses“ oder als Teil einer „Balkan-Mentalität“ deuten zu wollen, wäre weit gefehlt. Denn diese Strategie wählten die italienischen und deutschen Besatzer, um die durch eigene Einheiten angewandte Gewalt im Gegensatz dazu als ordnende und stabilitätsstiftende Einsätze zu vermitteln. ${ }^{62}$

Schließlich erfuhren auch Deutsche, die nicht an der Ostfront gedient hatten, durch den insgesamt vier Jahre andauernden Partisanenkrieg, in welchem die deutsche Wehrmacht und die Verbände der Waffen-SS zweitweise komplett die Kontrolle verloren und auf die Stufe der anderen Bürgerkriegsparteien abzugleiten drohten, eine Gewaltsozialisation, die Schmider als „Verrohung“ und „Brutalisierung“ bezeichnet. ${ }^{63}$

Bei allen vier Divisionen kann davon ausgegangen werden, dass Massaker und andere Kriegsverbrechen einerseits politische, aber auch ethnische Hintergründe haben konnten. Nicht nur für die muslimischen Divisionen, auch für die „Prinz Eugen“ geht Casagrande von solchen aus, ${ }^{64}$ da „sie [...] nicht nur Teil des nationalen Kriegs einer Besatzungsmacht [waren], sondern auch Teil eines ethnischen Konflikts miteinander konkurrierender ethnischer Gruppen “. ${ }^{65} \mathrm{Au}$ ßerdem wurden Kriegsverbrechen sowohl auf Befehl von Vorgesetzten als auch ohne konkreten Befehl verübt. So unterstreicht etwa Himmler in einem Schreiben an Phleps, dass der Krieg gegen die Partisanen mit zwei Methoden geführt

60 Vgl. Bougarel, Korb, Petke, Zaugg, Muslim SS Units, S. 265.

61 Vgl. Hoare, Bosnian Muslims, S. 46.

62 Vgl. Korb, Im Schatten des Weltkriegs, 17-19, 28f. Vgl. Bougarel, Korb, Petke, Zaugg, Muslim SS Units, S. 265.

63 Vgl. Schmider, Auf Umwegen zum Vernichtungskrieg?, S. 915, 918.

64 Vgl. Casagrande, Volksdeutsche SS-Division, S. 283.

65 Ebd., S. 283. 
werden sollte, einerseits mit einer „soldatisch-taktischen“, andererseits mit der „Methode der territorialen Befriedung, welche [...] den Gegner radikal mit den Wurzeln aushebt und durch die Art des Vorgehens das geistige Sprengpulver für die Verbände Tito‘s [sic] ist"“.66 Doch bis heute ist das Wissen um die Teilnahme an Kriegsverbrechen von „fremdvölkischen“ Angehörigen verschiedener Waffen-SS-Formationen und insbesondere der Motivation, die dahinter steckte, beschränkt. ${ }^{67}$ Einerseits ist dies dem erschwerten Zugang zu bestimmten Archiven geschuldet, ${ }^{68}$ andererseits wurden, wie beispielsweise im Fall der „Skanderbeg“, zahlreiche Akten in den letzten Kriegsmonaten vernichtet. ${ }^{69}$

Somit lässt sich nicht klären, welcher Einfluss auf die Soldaten stärker war, derjenige, den sie bereits von der Ostfront mitbrachten und an ihre Untergebenen weitergaben oder derjenige vor Ort, dem sie tagtäglich während mehrerer Jahre ausgesetzt waren. Was sich aber mit Sicherheit sagen lässt, ist, dass sich viele diesem „Strudel aus Gewalt und Gegengewalt“ nicht zu entziehen vermochten. ${ }^{70}$

\section{2 Ähnlichkeiten und Unterschiede zwischen den vier südosteuropäischen Divisionen}

\subsubsection{Zwei Stufen von Rekrutierungen}

Bei den hier vorgestellten Divisionen werden zwei Stufen von Rekrutierungen erkennbar. Bei der ersten Stufe handelt es sich um ein Abtasten der deutschen Verwaltung, SS und SD vor Ort, indem sie, zumeist auf freiwilliger Basis so genannte Selbstschutzeinheiten aufbauten: Der „volksdeutsche Selbstschutz“ im Banat, der makedonische "Selbstschutz“ oder die „Albanisch-muselmanische SS-Freiwilligen-Legion“ sind Beispiele dafür. ${ }^{71}$ In dieser Phase wurde oft auch

\footnotetext{
66 Vgl. Schreiben Himmler an Phleps, 10.5.1944, BArchB, R9361-III/547576, S. 2.

67 Vgl. Böhler, Gerwarth (Hgg.), The Waffen-SS. A European History, S. 1.

68 Zurzeit (2019) ist beispielsweise das Serbische Militärarchiv auch für Serben und erst recht für Ausländer nur bedingt oder gar nicht mehr zugänglich. Restriktionen wie ein Archivtag pro Woche schränken die Recherchemöglichkeiten stark ein. Ausländische Forscher warten oft monatelang und manchmal vergeblich auf eine Bewilligung ihrer Rechercheanträge.

69 Arnemann schrieb 1982 an Vopersal: „Wir übernahmen die Sicherung der Ortschaft, während im Laufe des Tages vom Stammpersonal „Skanderbeg“ schriftl. Material vernichtet wurde.“ Arnemann an Vopersal, 19.1.1982, BArchF, N 756/182a. Vgl. auch Zaugg, Albanische Muslime, S. 276.

70 Vgl. Schmider, Auf Umwegen zum Vernichtungskrieg?, S. 921.

71 Vgl. Zaugg, Albanische Muslime, S. 180-182. Vgl. Casagrande, Volksdeutsche SS-Division, S. 185. Im Banat auch „Volksdeutscher Heimatschutz“ genannt. Vgl. ebd.
} 
für lokale Polizeieinheiten geworben - insbesondere ältere Jahrgänge waren dafür vorgesehen. ${ }^{72}$ Die zweite Phase bildete die eigentliche Rekrutierung für eine der vier südosteuropäischen Waffen-SS-Divisionen. Hier kam es bei allenvorgestellten Divisionen zu Zwangsmaßnahmen, im Falle der Division „Skanderbeg“ erließ die albanische Regierung sogar einen allgemeinen Rekrutierungsbefehl. ${ }^{73}$ Die Eintritte in eine dieser Divisionen folgten aber kaum mehr einer politischen Überzeugung oder der Freiwilligkeit, vielmehr versuchte die Waffen-SS-Führung die potentiellen Rekruten mit der Verteidigung des Eigenen gegen das Fremde, in Gestalt der Kommunisten, und durch die Instrumentalisierung bereits schwelender interethnischer Konflikte zu motivieren. ${ }^{74}$

\subsubsection{Zusammenarbeit mit lokalen Eliten}

Vor Ort arbeitete die Waffen-SS eng mit lokalen Organisationen zusammen. Gerade die von der „Volksdeutschen Mittelstelle“ unter Leitung von SS-Obergruppenführer Werner Lorenz und Stabschef SS-Oberführer Hermann Behrends ${ }^{75}$ eingesetzten „Volksgruppenführer“ waren sowohl bei den „Volksdeutschen“ als auch den Muslimen der jeweiligen Regionen für den Erfolg der Rekrutierungen von Bedeutung. Sie genossen das Vertrauen - zumindest von Teilen - der Bevölkerung. Einige hatten diese Funktion bereits vor dem Krieg innegehabt; so beispielsweise Sepp Janko, der im Juni 1939 von der „volksdeutschen“ Gemeinschaft in Serbien und im Banat zu ihrem „Volksgruppenführer“ gewählt worden war. ${ }^{76}$ Für die Muslime in Nordkosovo/Südserbien bzw. der Sandžak-Region hatte „Volksgruppenführer“ Ali Beg Draga diese Funktion inne, für die „volksdeutsche“ Gemeinschaft im NDH Branimir Altgayer, Sepp Janko für die „volksdeutsche“ Bevölkerung im Banat und Andreas Schmidt für die Rumäniendeutschen.

Daneben setzten sich weitere prominente Organisationen lokaler Eliten für die Rekrutierungen in die Waffen-SS ein; so beispielsweise das „Albanische Komitee zur Verteidigung Kosovos“ und die „Zweiten Liga von Prizren“, indem sie ganze Jahrgänge zur Verfügung stellten, den Dienst bei der SS ab März 1944 als obligatorischen Militärdienst betrachteten und sich als tatkräftige Parallelinstitution zur Regierung in Tirana präsentierten. Auch in Bosnien gründete die Zusammenarbeit

72 Vgl. Zaugg, Albanische Muslime, S. 182.

73 Vgl. Sitzung des „Zentralkomitees zur Verteidigung Kosovos“, Nr. 14, 30.03.1944 A.Q.SH., F. 147, V. 1944 D I-165, S. 15.

74 Vgl. Casagrande, Volksdeutsche SS-Division, S. 325.

75 HSSPF Serbien, Montenegro und Sandžak.

76 Vgl. Janko, Weg und Ende der deutschen Volksgruppe, S. 38. 
mit deutschen Dienststellen auf der Idee, durch deutsche Hilfe ein eigenes „bosnisches“ Militär aufbauen zu können. ${ }^{77}$ Für die Rekrutierung der bosnischen Muslime waren der „Merhamet - Muslimansko Dobrotvorno Društvo“, ein „muslimischer Wohltätigkeitsverein“ mit Sitz in Sarajevo und dessen Präsident Hafiz Muhamed Pandža von zentraler Bedeutung. ${ }^{78}$

Wenn man die Rekrutierungsphasen der vier hier vorgestellten Divisionen betrachtet und die Art und Weise, in der die Waffen-SS als Institution in die jeweiligen Bevölkerungsgruppen eingeführt wurde, wird deutlich, dass die Deutschen vor Ort auf eine starke lokale Unterstützung angewiesen waren: Je besser die Zusammenarbeit mit den lokalen Eliten funktionierte, desto zahlreicher erschienen die Rekruten. Diese lokalen Institutionen wiesen zwar unterschiedliche Entstehungsgeschichten und Strukturen auf, in ihrem Vorgehen und der Art der Propaganda, wie Männer vor Ort rekrutiert werden sollten, glichen sich aber ihre Vorgehensweisen: Immer ging es darum, die Vorherrschaft der eigenen „Volksgruppe“ gegenüber den anderen in diesen Räumen ansässigen Ethnien zu sichern. Sei es, indem man die „Volksdeutschen“ glauben ließ, dass sie in einer paneuropäischen Armee für ein neues Europa unter deutscher Herrschaft kämpfen würden; indem man den bosnischen Muslimen Autonomie versprach oder den Albanern das Fortbestehen eines „großalbanischen“ Staates nach dem Krieg zusicherte.

Wie bei der Untersuchung zu den einzelnen Divisionen gezeigt erwiesen sich diese Institution lokaler Eliten als durchaus aktive Akteure mit klar definierten Intentionen, einer eigenen Handlungsmacht und großem Einfluss. Einen Spezialfall bilden lokale Clanchefs in den Gebieten Nordalbaniens und Kosovo, die sich manchmal unabhängig von übergeordneten lokalen Strukturen für oder gegen eine Zusammenarbeit mit den Deutschen entschieden. ${ }^{79}$ In den Gebieten „Neualbaniens“, welches weder durch staatliche noch durch lokale, übergeordnete Institutionen, sondern in erster Linie durch die Clanchefs selbst kontrolliert wurde, gestaltete sich daher die Rekrutierungsarbeit der Vertreter der Waffen-SS am schwierigsten. Clanmitglieder waren gezwungen, so zu handeln, wie die Clan-

77 Vgl. Reisebericht SS-Hauptsturmführer Hasan Bajralitarović [Bajraktarević] an Phleps, 15.11.1943, BArchB, NS19/2601, Bl. 59.

78 Vgl. Zaugg, Albanische Muslime, S. 144. Vgl. Sundhaussen, Waffen-SS in Kroatien, S. 178 f. Vgl. Abschrift Besprechung „Merhamet“, Mehmed Tokić und 369. Inf.Div., 17.9.1943, BArchB NS19/3893, Bl. 16.

79 Vgl. Amery, Sons of the Eagle, S. 164. Abaz Kupi dient hier als gutes Beispiel: Er arbeitete zeitweise mit der Britischen Militärmission (SOE) zusammen, konnte sich aber nicht dazu durchringen, die Zusammenarbeit mit den Deutschen ganz aufzulösen. Vgl. Amery, Sons of the Eagle, S. 221f., 230, 241. 
vorsteher es beschlossen hatte. Schmidhuber war am Ende seiner Dienstzeit als Kommandeur der „Skanderbeg“ der Meinung, dass man daher die Clanchefs mit Gold hätte überzeugen müssen, um ein besseres Rekrutierungsergebnis zu erreichen. ${ }^{80}$

Obwohl die lokalen Institutionen alle die Vormachtstellung der eigenen Gruppe als Ziel verfolgten, unterschieden sie sich insbesondere in ihrer inneren Struktur: Der bosnische „Merhamet“ etwa baute auf dem muslimischen Glauben auf und kann als religiöse Organisation bezeichnet werden, während die „Zweite Liga von Prizren“ vor allem eine politische Organisation war. Die „volksdeutsche Volksgruppenführung“ wiederum war von rassischen Elementen geprägt. Gemeinsam ist all jenen Gruppen lokaler Eliten, dass sie eine Handlungsmacht entfalteten, die es ihnen teilweise ermöglichte, auf Augenhöhe mit den Deutschen eigene Forderungen zu stellen und durchzusetzen. Mitnichten waren sie bloße „Schachfiguren“, als welche sie rückblickend im Bericht zur „Entwicklung der militärischen Lage in Albanien im Herbst 1944“ 'bezeichnet wurden. ${ }^{81}$

\subsubsection{Verhandlungen mit Regierungen}

Neben Verhandlungen mit lokalen Institutionen waren die Deutschen in Staaten wie dem NDH, „Großalbanien“, Rumänien oder Ungarn auch auf die Zusammenarbeit mit den Regierungen des jeweiligen Landes angewiesen. Wie in den Kapiteln zur „Prinz Eugen“, zur „Handschar“ und zur „Skanderbeg“ gezeigt, verfolgten die Regierungen aber oft andere Ziele als die Werber der Waffen-SS. Phleps etwa war während der Aufstellung der „Handschar“ sogar der Meinung, dass es sich bei der kroatischen Regierung um einen der Hauptkontrahenten der Aufstellung handelte, da diese versucht hätte, die Aufstellung der Division „mit allen Mitteln zu unterbinden“. Stets neue Einwände und Forderungen von Seiten der Regierung verzögerten den Aufbau der Division, und mit deutschen Dienststellen vereinbarte Abmachungen wurden nicht eingehalten. ${ }^{82}$

Auch in Albanien gestaltete sich die Zusammenarbeit mit der Regierung schwierig. Denn diese sah im Aufbau der „Skanderbeg“ vor allem eine Gelegen-

80 Schmidhuber, „Zusammenfassender Bericht“, 2.10.1944, BArchF, RS 3-21/1, S. 3.

81 OB Südost, Bericht „Entwicklung der militärischen Lage in Albanien im Herbst 1944“, undatiert, BArchF, RW 40/116a, Bl. 14. Vgl. hierzu bspw.: Eva Anne Frantz: Catholic Albanian Warriors fort he Sultan in late-Ottoman Kosovo: the Fandi as a socio-professional group and their identity patterns, in: Grandits, Clayer, Pichler, Conflicting Loyalties, S. 182-201.

82 „Zwischenbericht über Werbeaktion muselmanischer Freiwilliger“, Phleps an Chef des SSFührungshauptamtes, SS-Gruppenführer Jüttner, 19.4.1943, BArchB NS19/2601, Bl. 8. 
heit, einen Kern für eine zukünftige nationale Armee zu schaffen und in der Zusammenarbeit mit den Deutschen die Möglichkeit, „Großalbanien“ über das Kriegsende hinwegzuretten. Im Gegensatz zur Regierung Ante Pavelićs war sie nicht faschistisch eingestellt, sondern verfolgte lediglich nationalistische Ziele. Dass sie innerhalb des albanischen Staates nur geringe Bedeutung besaß und oben genannte lokale Eliten die eigentliche Machtbasis für die Rekrutierungen bildeten, zeigen die zahlreichen Regierungswechsel während der italienischen und später deutschen Besatzungszeit. ${ }^{83}$

In Rumänien hatte die Regierung Antonescu darum gebeten, die Rekrutierungen für die Waffen-SS mit Diskretion durchzuführen, da solche Rekrutierungen für die Armee eines verbündeten Staates ein innenpolitisch äußerst brisantes Thema darstellten. Aus diesem Grund wurde die Waffen-SS in Werbereden und -unterlagen oft nicht namentlich erwähnt. ${ }^{84}$ Nach Stalingrad forderte Himmler Berger auf, 20-30.000 Rumäniendeutsche und 30-50.000 Ungarndeutsche zu rekrutieren, obwohl noch Anfang 1942 der deutsche Gesandte in Bukarest, Manfred von Killinger, dringend von Massenrekrutierungen solcher Größenordnung abgeraten hatte. Trotz Einwänden der rumänischen und ungarischen Regierung rekrutierte Berger im Laufe des Jahres 1943 rund 50.000 „Volksdeutsche“ aus Rumänien, ${ }^{85}$ und durch eine zwischenstaatliche Vereinbarung mit Ungarn erhielt das Deutsche Reich ab 30. April 1944 sogar Zugriff auf alle männlichen ungarischen „Volkdeutschen“ zwischen 17 und 55 Jahren. Insgesamt dienten rund 120.000 Ungarndeutsche in der Waffen-SS. ${ }^{86}$ Die Zahl der aus Ungarn und der Slowakei rekrutierten Soldaten für die „Prinz Eugen“ blieb mit 582 und 662 Mann allerdings sehr gering. ${ }^{87}$

\subsubsection{Kompetenzstreitigkeiten zwischen deutschen Dienststellen}

Ein Merkmal, das sich wie ein roter Faden durch sämtliche Rekrutierungen Südosteuropas zieht, sind die Kompetenzstreitigkeiten zwischen den einzelnen deutschen Dienststellen. Nicht nur zwischen dem Auswärtigen Amt und der Waffen-SS, auch zwischen der Wehrmacht und der Waffen-SS entbrannte zuweilen Streit bezüglich der vorhandenen Personalressourcen bzw. über die Frage, wo und unter welchen Bedingungen diese rekrutiert werden durften. Allerdings muss hinsichtlich der

83 Vgl. Zaugg, Albanische Muslime, S. 72, 100, 204.

84 Vgl. Milata, Zwischen Hitler, Stalin und Antonescu, S. 167, 169.

85 Vgl. ebd., S.131f.

86 Vgl. Krisztián Ungváry, Kriegsschauplatz Ungarn, S. 862.

87 Vgl. Casagrande, Volksdeutsche SS-Division, S. $211 \mathrm{f}$. 
vier Balkan-Divisionen festgehalten werden, dass sich letzten Endes Himmler stets gegen seine Opponenten durchsetzen konnte. ${ }^{88}$

Als einer der größten Widersacher der Werbungen für die Waffen-SS in Südosteuropa galt der deutsche Gesandte in Agram, Siegfried Kasche. Bereits 1942 mischte er sich in die Rekrutierungsanstrengungen der Waffen-SS für die „Prinz Eugen“ ein. Im „souveränen“ NDH schienen ihm solche Rekrutierungen unangebracht. ${ }^{89}$ In diese erste Auseinandersetzung waren schließlich nebst Kasche SS-Obersturmführer Günther Herrmann, Unterstaatssekretär Martin Luther, SS-Obergruppenführer und General der Waffen-SS Karl Wolff sowie Berger involviert. ${ }^{90}$ Auch im Falle der Rekrutierungen für die Division „Handschar“, ein Jahr später, versuchte Kasche das Vorgehen der Waffen-SS zu sabotieren; etwa indem er über das Auswärtige Amt der Ustaša davon abriet, enge Bindungen mit der SS einzugehen. Berger hingegen warnte den kroatischen Botschafter in Berlin, Mile Budak, vor einer Zusammenarbeit mit Unterstaatssekretär Luther. ${ }^{91}$ Obwohl Berger nach Möglichkeit versuchte, die Verhandlungen bezüglich der Werbung von albanischen Muslimen aus der Sandžak-Region über den Beauftragten des Auswärtigen Amtes in Belgrad zu führen, ${ }^{92}$ mischte sich Kasche auch hier ein, indem er etwa beim Auswärtigen Amt kritisierte, der lokale Rekrutierungsleiter von Krempler wäre im Sandžak-Gebiet durch „äußerst nachteilige Methoden bei der Werbung“ aufgefallen. ${ }^{93}$

\subsubsection{Die deutschen Besatzer als „Erlöser“: Betonung ethnischer und nationaler Interessen}

In allen Rekrutierungsregionen der hier untersuchten Divisionen wurden die einmarschierenden deutschen Truppen von weiten Teilen der später rekrutierten „Volksgruppen“ als „Erlöser“ wahrgenommen, welche die „Volksdeutschen“ bzw. bosnische und albanische Muslime vom Joch der Serben und Kroaten befreiten. ${ }^{94}$ Im Frühjahr 1941 erwarteten Teile der „,volksdeutschen“ Bevölkerung, bei-

88 Vgl. Rempel, Gottlob Berger and the Waffen-SS Recruitment, S. 107-117.

89 Vgl. Sundhaussen, Waffen-SS in Kroatien, S. 178.

90 Vgl. bspw. Luther an SS-Obergruppenführer Wolff, 5.11.1944, BArchB, NS19/319, Bl. 61.

91 Vgl. Korb, Im Schatten des Weltkriegs, S. 112.

92 Berger an das AA, „Betreff: Freiwillige für die 13. (kroatische) SS-Division aus dem Sandžakgebiet“, 9.4.1943, PAAA, R100998, H297616.

93 Gesandter Kasche an AA, 15.9.1943, PAAA, Inland IIg R100998.

94 Vgl. Casagrande, Unsere Gegner, S. 164. Vgl. Avni Gjilani an Jacomoni, 16.4.1941, A.Q.SH., F.161, 1941, D 1078, S. 7. 
spielsweise in der Bačka und im Banat, den Einmarsch deutscher Truppen und nahmen teilweise aktiv am Kampfgeschehen teil. ${ }^{95}$ Auch zahlreiche bosnische Muslime legten beim Einmarsch deutscher Truppen ein unterstützendes Verhalten an den Tag. ${ }^{96}$ Und selbst in der Kosovo- und Sandžak-Region kämpften albanische Freischärler im April 1941 an der Seite deutscher Truppen, und in den Städten wurden deutsche und italienische Flaggen gehisst. ${ }^{97}$

Es erstaunt daher nicht, dass die Betonung des Ethnischen von den Deutschen auch bei der Aufstellung der südosteuropäischen Divisionen einen hohen Stellenwert einnahm: Einerseits stellte diese Akzentuierung die wichtigste Gemeinsamkeit der vier Waffen-SS-Divisionen dar, andererseits wohl auch den augenfälligsten Unterschied: So zielte die Namensgebung aller vier Divisionen auf ethnische Besonderheiten und Traditionen: „Prinz Eugen“ war in Anlehnung an den „Befreier des Balkans“ von den Osmanen, Prinz Eugen von Savoyen, gewählt worden. Er war es auch, der deutsche Kolonisten dort ansiedelte. „Handschar“ und „Kama“ bezeichnen traditionelle bosnische, ursprünglich arabische Waffen, und „Skanderbeg“ meint den bis heute in Kosovo und Albanien verehrten Nationalheld Iskander Beg bzw. Gjergj Kastrioti, der im 15. Jahrhundert 25 Jahre lang Gebiete im Zentralbalkan gegen die Osmanen verteidigt hatte. ${ }^{98}$ Die Anknüpfung an alte Traditionen - der deutschen Kolonisation im Falle der „Prinz Eugen“ oder dem Verteidigungskampf gegen die osmanischen Eroberer im Falle der „Skanderbeg“ - verfolgten das Ziel, die Rekrutierten oder $\mathrm{zu}$ Rekrutierenden von anderen ethnischen Gruppen abzugrenzen und die deutsche Unterstützung in ihrem Kampf um Autonomie zu unterstreichen. ${ }^{99}$ Bei allen vier Divisionen wurden auf diese Weise nationalistische Tendenzen verstärkt. ${ }^{100}$ Ein wichtiges gemeinsames Merkmal der bosnischen „Handschar“ und „Kama“ und der albanischen „Skanderbeg“ war denn auch die Hoffnung, die Aufstellung der jeweiligen SS-Division sei die Keimzelle für eine spätere nationale

95 Vgl. Casagrande, Volksdeutsche SS-Division, S. 160, 167.

96 Vgl. Al-Husaini an von Weizsäcker, 9.6.1942, Höpp, Mufti-Papiere, S. 43.

97 Vgl. Kollegger, Albaniens Wiedergeburt, S. 66.

98 Vgl. hierzu ausführlich Schmitt, Skanderbeg, Regensburg: Friedrich Pustet 2009. Vgl. Zaugg, Albanische Muslime, S. 35. Vgl. Casagrande, Volksdeutsche SS-Division, S. 325. Vgl. zur Namensgebung als Anbiederung an nationalistische kollaborationswillige Kreise und die Förderung der Identifikation lokaler Rekruten mit den jeweiligen Verbänden auch Leleu, La Waffen-SS, S. 432. 99 Vgl. Casagrande, Volksdeutsche SS-Division, S. 188.

100 Vgl. etwa Malcolm, Kosovo, S. 304. 
Armee - nach Erreichung eines Autonomiestatus bzw. nationaler Unabhängigkeit mithilfe der Deutschen. ${ }^{101}$

Die Betonung ethnischer Herkunft fand ihren Ausdruck aber auch in der Uniformierung, beispielsweise dem Fez oder der albanischen Filzmütze, und den Emblemen der einzelnen Divisionen: Die Abzeichen am Kragenspiegel zeigten eine Odalrune für die „Prinz Eugen“, den bosnischen Krummdolch für die „Handschar“, den albanischen Doppeladler für die „Skanderbeg“ sowie eine Sonne für die „Kama“. ${ }^{102}$ Allerdings unterliefen den Verantwortlichen dabei auch peinliche Fehler: In einer voreiligen Aktion hatten sie für die Division „Skanderbeg“ dieselben Feze angefordert wie sie bereits bei der Division „Handschar“ verwendet wurden; ein Fauxpas ohnegleichen. Der albanische Vizeaußenministers Mehdi Bej Frashëri meldete umgehend, solche Kopfbedeckungen seien äußerst ungeeignet, würden sie doch stark an die osmanische Herrschaft erinnern. Auf deutscher Seite wurden Frashëris Einwände bedauernd zur Kenntnis genommen und beteuert, „dass bei der Einführung des Fez als militärische Kopfbedeckung bei muselmanischen SS-Formationen gerade der Wunsch maßgebend gewesen sei, auf die nationalen und religiösen Gefühle dieser fremdvölkischen SS-Männer Rücksicht zu nehmen“. Daraufhin verzichtete man in der „Skanderbeg“ ganz auf Feze, während sie sich in der „Handschar“ zum optischen Hauptmerkmal entwickelten. ${ }^{103}$

Trotz all dieser ethnischen Differenzierungen findet sich in den Quellen der Ausdruck „Schwesterdivision“, der auf die verwandtschaftliche Nähe zwischen den muslimischen südosteuropäischen Divisionen einerseits, aber auch zwischen ihnen und der „Prinz Eugen“ andererseits hinweist. ${ }^{104}$

\subsubsection{Das Prinzip der „Freiwilligkeit“: Motivation versus Zwang}

In den Kapiteln zu den einzelnen Divisionen wurde das jeweilige Spannungsfeld von unterschiedlichen Motivations- und Zwangsfaktoren ausgebreitet und ausgelotet. Hier soll zusammenfassend noch einmal auf diese Faktoren eingegangen werden. Grob lassen sich Zwänge in Form von politischem, wirtschaftlichem, sozialem, persönlichem Druck, von physischer und psychischer Gewalt

101 Vgl. Ferhadbegović, Schuldig, im Namen des Volkes, S. 1. Vgl. Zaugg, Albanische Muslime, S. $105,139 \mathrm{f}$.

102 Vgl. Casagrande, Volksdeutsche SS-Division, S. 325.

103 Vgl. Schreiben Andor Hencke, Leiter Politische Abteilung, an das AA, Inland IIc, 4.3.1944, PAAA, R100649, Bl. 000022.

104 Vgl. bspw. Kumm, Vorwärts Prinz Eugen, S. 335. 
bzw. Gewaltandrohung sowie auch der Gefahr, Opfer einer anderen Gruppierung zu werden, erkennen. Motivationsgründe konnten ebenfalls politischer, wirtschaftlicher oder persönlicher sowie materieller oder immaterieller Natur sein: Die Aussicht, nach Kriegsende einem eigenen autonomen Staat anzugehören, gegen den „Bolschewismus“ zu kämpfen, eine militärische Ausbildung, Waffen, Ausrüstung, Sold, Nahrung und Familienunterstützung zu erhalten, sich beim Gegner bereichern zu können oder aber jemanden zu rächen, zählten zu diesen Beweggründen. ${ }^{105}$

Dass die Namensgebung so genannter „Freiwilligen“-Divisionen oft nicht die Realität widerspiegelte, sondern lokale Eliten, wie „Volksgruppenführer“, der „Merhamet“ oder die „Zweite Liga von Prizren“ und lokale SS-Institutionen massiven Druck auf bestimmte Bevölkerungsgruppen ausübten, davon zeugt etwa die bereits erwähnte Aussage Schmidhubers. ${ }^{106}$ Oft ist daher auch von einem „Zwang zur Freiwilligkeit“ die Rede. ${ }^{107}$ Vielfach lassen sich Umstände, die für einen Beitritt in eine der Waffen-SS-Divisionen sprachen, jedoch nicht eindeutig den Spektren „Zwang“ oder „Freiwilligkeit“ zuordnen, da die Gründe für einen Beitritt vielschichtig und fließend waren und die Entscheidung eines Individuums ein Zusammenspiel all jener Faktoren darstellen konnte.

Eine frühe Form von Druck auf moralischer Ebene lässt sich bereits Anfang 1940 bei Werbern in Deutschland nachweisen. Allerdings könne, so Wegner, zu diesem Zeitpunkt noch nicht von einem Zwangscharakter gesprochen werden, wie er bei der Aufstellung späterer Divisionen auftrat. ${ }^{108}$ Diese Art von Druck hatte eher Appellcharakter: Etwa indem der Dienst in der Waffen-SS als „Ehrensache“ dargestellt wurde, wie dies beispielsweise oft bei Rekrutierungen von „Volksdeutschen“ der Fall war. ${ }^{109}$

Druckmittel in Form konkreter Drohungen, beispielsweise der Androhung körperlicher Gewalt oder der angekündigten Zerstörung von Eigentum, können für Südosteuropa spätestens seit den Rekrutierungen „Volksdeutscher“ nach dem Balkanfeldzug 1941 nachgewiesen werden. Diese stellten ein gängiges Mittel

105 Vgl. bspw. Casagrande, Volksdeutsche in der Waffen-SS, S. 69f. Vgl. Milata, Zwischen Hitler, Stalin und Antonescu, S. 174-202.

106 Vgl. Kriegsgefangenenbericht II, August Schmidhuber, 19.8.1945, VA HEM.OK.BOJCKA, 72/1/2/3. Vgl. auch Sundhaussen, Waffen-SS in Kroatien 1941-1945, S. 177.

107 Vgl. Casagrande, Südtiroler in der Waffen-SS, S. 55.

108 Vgl. Wegner, Soldaten, S. 275. Vgl. Casagrande, Südtiroler in der Waffen-SS, S. 36. Vgl. zur Ausübung von Druck auf sehr junge Rekruten auch Rempel, Gottlob Berger and the Waffen-SS Recruitment, S. 114.

109 Vgl. Casagrande, Volksdeutsche in der Waffen-SS, S. 192. 
dar, um geforderte Kontingente zu erreichen. ${ }^{110}$ Rekrutierungszwang in Form von Gewaltandrohung war aber nicht auf Südosteuropa beschränkt und lässt sich auch andernorts finden; etwa bei der Rekrutierung estnischer Soldaten oder in Südtirol. ${ }^{111}$

Zum Rekrutierungszwang zählte schließlich auch die Einberufung bestimmter Jahrgänge, wie dies etwa für die Grenzregionen „Großalbaniens“ oder dem Banat der Fall war. ${ }^{112}$

Am anderen Ende der Skala stehen die freiwilligen Beitritte. SS-Hauptsturmführer Hasan Bajraktarević erklärte die Beweggründe bosnischer Freiwilliger mit folgenden Worten: „Ihre [der bosnischen Rekruten] Interessen und Verlangen jedoch waren minimal: öffentliche Sicherheit und Ordnung, ein Stückchen Brot zu Hause, und darauf erst Kampf um höhere Ideale. In diesem Sinne waren sie [die Rekruten] bereit, ihr Schicksal vollkommen in Gottes und der Deutschen Hände zu legen. “113

Die Bedrohung des eigenen Besitzes, der Familie, des Heims oder des eigenen Dorfes durch gegnerische Gruppierungen kann zwar als Handlungszwang gewertet werden - doch auch hier erfolgte der Eintritt in die Waffen-SS freiwillig. Diese Art von „Freiwilligkeit“ wurde durch äußere Umstände erzwungen, wie von SS-Brigadeführer und Generalmajor der Waffen-SS Ernst Fick in einem Schreiben an Himmler treffend beschrieben: Die Muslime würden häufig zwangläufig der Waffen-SS oder einer Partisaneneinheit beitreten, um nicht von den Ustaša, den Četniks oder den Partisanen ermordet zu werden. ${ }^{114}$ Viel stärker als politische Präferenzen aus der Vorkriegszeit führten die tägliche Bedrohung und erlebte Gewalt zur Meldung in eine der Waffen-SS-Divisionen, „da Überlebenswille und Angst das Verhalten der Bevölkerung diktierten“, wie Korb betont. ${ }^{115}$ Ob jemand sich für die Ustaša, die Čentiks, die Partisanen oder aber eine Waffen-

110 Vgl. Casagrande, Unsere Gegner, S. 163. Vgl. auch Bericht Vopersal „7. SS-FreiwilligenGebirgs-Division ,Prinz Eugen““, BArchF, N756/149a.

111 Vgl. Thonas Hiio, Estnische Einheiten der Waffen-SS, in: Schulte, Lieb, Wegner, (Hgg.), Die Waffen-SS. Neue Forschungen, S. 153. Vgl. Casagrande, Südtiroler in der Waffen-SS, S. 55-58.

112 Vgl. Sitzung des „Zentralkomitees zur Verteidigung Kosovos“, Nr. 14, 30.03.1944 A.Q.SH., F. 147, V. 1944 D I-165, S. 15. Bericht Vopersal „7. SS-Freiwilligen-Gebirgs-Division ,Prinz Eugen““, BArchF, N756/149a. Vgl. zur abnehmenden Rekrutierungsbereitschaft für die WaffenSS allgemein: Höhne, Orden unter dem Totenkopf, S. 439.

113 Reisebericht SS-Hauptsturmführer Hasan Bajralitarović[Bajraktarević] an Phleps, 15.11.1943, BArchB, NS19/2601, Bl. 59.

114 SS-Brigadeführer und Generalmajor der Waffen-SS Ernst Fick an Himmler, 16.3.1944, BArchB, NS 19/2601, Bl. 82. Vgl. auch Nedim Salihbegović, „Bericht zur Lage“, 25.9.1943, BArchB, NS 19/2601, Bl. 30.

115 Korb, Im Schatten des Weltkriegs, S. 87. 
SS-Einheit rekrutieren ließ, hing vielfach auch damit zusammen, welche Gruppe den Betroffenen am stärksten schien und für sie in erreichbarer Distanz lag. ${ }^{116}$ Solche Entscheidungen, sich für die eine oder andere Gruppe rekrutieren zu lassen, entzweiten zuweilen ganze Familien, wie etwa im Falle der Familie Bernwald oder der Familie Floritsch. ${ }^{117}$

Um freiwillige Beitritte zu fördern, griffen die deutschen Besatzer auch auf ihre „Vorgänger“ zurück: Bei weiten Teilen der slawischen und albanischen Bevölkerung genossen die Deutschen einen guten Ruf, weil man ihre Herrschaft mit derjenigen Österreich-Ungarns gleichsetzte. ${ }^{118}$ Sie waren der Überzeugung, die Nationalsozialisten hätten mit dem Balkanfeldzug das Erbe Österreichs angetreten. Die Zeit österreichisch-ungarischer Herrschaft war ihnen in guter Erinnerung, da sie diese Ära mit wirtschaftlicher, sozialer und politischer Stabilität verbanden. ${ }^{119}$ Der Rückbezug auf Österreich-Ungarn zieht sich denn auch wie ein roter Faden durch die Rekrutierungen für die Waffen-SS in Südosteuropa. ${ }^{120}$

Neubacher schätzte allerdings rückblickend das Rekrutierungspotential, das sich aus dem Zerfall des Ersten Jugoslawiens in deutsche Verbände ergeben hätte, noch wesentlich höher ein. Dass dieses nicht genutzt bzw. in seinen Worten „vergeudet“ wurde, schrieb er „der schlechten Politik der Achsenmächte“ zu. Denn Tito wiederum habe dieses Potenzial genutzt, indem er

mit ,dialektischer` Treffsicherheit die jugoslawische Föderation proklamiert und damit zwischen der zentralistischen groß-serbischen These, die versagt hatte, und der Antithese der Zertrümmerung, der die Ernüchterung folgte, eine Synthese aufgerichtet [hatte], die Werbekraft besaß. Die Bedeutung dieses Vorgangs wurde im deutschen Hauptquartier unterschätzt. ${ }^{121}$

Den Beitritt in die Waffen-SS erleichterte auch die Tatsache, dass die lokale Bevölkerung in den südosteuropäischen Grenzregionen seit Generationen wech-

$116 \mathrm{Vgl}$. Korb, Im Schatten des Weltkriegs, S. 87. Zu dieser Entscheidung auch Rgt.Kdr. 4. Rgt. „Brandenburg“: „Viele Partisanen sind es erst durch ein Zusammenwirken verschiedener Umstände geworden: Ustascha-, Muselmanen- oder Cetnik-Greuel, Not und Hunger, Terror und Zwang durch andere Partisanen. Sie bleiben Partisanen, weil der Weg zurück durch die deutschen Befehle verbaut ist. Sie haben Heimat und Familie verloren, so kämpfen sie bis zum Tod.“ Zitiert nach Schmider, Auf Umwegen zum Vernichtungskrieg?, S. 912.

117 Vgl. Bernwald, Muslime, S. 36, 59 f.

118 Vgl. Tamara Scheer, A Reason to Break the Haag Convention?, S. 1011f. Vgl. Franziska Zaugg, „Ruhe, Sicherheit und Gerechtigkeit“, S. 441-448.

119 Vgl. Nedim Salihbegović, „Bericht zur Lage“, 25.9.1943, BArchB, NS 19/2601, Bl. 29.

120 Vgl. Leleu, Jenseits der Grenzen, S. 36.

121 Neubacher, Sonderauftrag Südost, S. 129. 
selnden Fremdherrschaften ausgesetzt war und das Söldnerwesen im Dienste fremder Großmächte daher eine lange Tradition besaß. Stammes-, regional- bzw. nationalpolitische Ziele fanden im Abwägen der Eliten, ob und wie weit mit einer Großmacht kollaboriert und ob aus den eigenen Reihen Soldaten geschickt wurden, ihren Niederschlag. ${ }^{122}$ In den Clan-dominierten Gebieten Nordalbaniens und Kosovo ergab sich daraus eine weitere Besonderheit: Ein „freiwilliger“ Beitritt konnte auch die Entscheidung des Clanchefs, aber nicht unbedingt des Individuums, bedeuten. Doch der Bezug zur Gruppe war auch in anderen Gebieten Südosteuropas oft stärker als die persönliche Präferenz: Je mehr sich beispielsweise Gewalt im NDH, in Serbien, „Großalbanien“ oder Rumänien gegen ganze ethnische Gruppen richtete, desto weniger spielten individuelle Überlegungen eine Rolle. $^{123}$

Weiter ist festzuhalten, dass, wie etwa im Falle der „Volksdeutschen“ Rumäniens, ${ }^{124}$ viele Meldungen freiwillig waren, sich die jungen Rekruten aber zum Zeitpunkt der Rekrutierung nicht bewusst waren, dass es nach dem Eintritt in die Waffen-SS kein Zurück mehr geben würde. ${ }^{125}$ Andere wiederum ließen sich lieber für die Waffen-SS rekrutieren, um dem Dienst in einer der nationalen Armeen zu entgehen, da sie meinten, dort aus verschiedenen Gründen, etwa aufgrund erniedrigender Behandlung, einem viel tieferen Sold oder geringerer Überlebenschancen, schlechter gestellt zu sein. ${ }^{126}$

$\mathrm{Zu}$ den Gründen, der Waffen-SS freiwillig beizutreten, zählte schließlich auch der bereits erwähnte Wunsch, entweder einen autonomen Staat (Bosnien) aufzubauen oder im Falle Kosovos und angrenzender Gebiete bei „Großalbanien“ zu verbleiben. So stellte man in italienischen Kreisen im Herbst 1943 fest: „Die Kosovaren sind in ihrer Gesamtheit germanophil. Denn sie fürchten, dass ein Sieg der Alliierten zur Herrschaft der Serben zurückführen würde. “127 Bereits Mussolini hatte diesen Irredentismus im Juni 1939 als „ein kleines Licht am Ende eines dunklen Ganges“ bezeichnet. Es stellte „das ideale Lockmittel“ dar, wenn es darum ging, deutsch-italienische Interessen auf dem Balkan zu verwirklichen und die Rekrutierungsbereitschaft von Bosniern und Albanern zu

122 Vgl. bspw. Schmidhuber, „Zusammenfassender Bericht“, 2.10.1944, BArchF, RS 3-21/1, S. 3. 123 Vgl. Korb, Im Schatten des Weltkriegs, S. 87. Vgl. Milata, Rumäniendeutsche Freiwillige in der Waffen-SS, S. $224 \mathrm{f}$.

124 Vgl. ebd.

125 Vgl. Milata, Zwischen Hitler, Stalin und Antonescu, S. 2.

126 Vgl. Casagrande, Unsere Gegner, S. 169. Vgl. Milata, Zwischen Hitler, Stalin und Antonescu, S. 2, 176.

127 Vgl. Relazione politica sull'Albania, 30.10.1943, AUSSME, I3/b13/f1, S. 4. 
erhöhen. ${ }^{128}$ Die deutschen Besatzer nutzten solche Ängste gezielt für die geplanten Rekrutierungen.

Sehr konkrete Wünsche, die für einen Beitritt sprachen, waren die Aussicht auf eine militärische Ausbildung nach westeuropäischem Vorbild, auf Bewaffnung und Ausrüstung, auf Nahrungsmittel für sich und die Angehörigen sowie auf einen regelmäßigen Sold und Familienunterstützung. Vorgesehen waren auch Zahlungen bei Todesfall und Invalidität. ${ }^{129}$

Nicht zu vernachlässigen ist dabei die Absicht, in den bereits seit langem schwelenden interethnischen Konflikten durch die Rückendeckung eines Koalitionspartners in eine Position der Stärke zu gelangen und so unerwünschte „Nachbarn“ vertreiben zu können. Dieses Verhalten war nicht in erster Linie politischen Überlegungen geschuldet, sondern baute auf einem Verteidigungsgedanken auf - und manchmal auch auf der Absicht, an den Besitz bzw. an Grund und Boden des Gegners zu gelangen.

Schließlich soll noch erwähnt werden, dass in Südosteuropa nicht nur die Deutschen unter Zwang rekrutierten. Auch kommunistische, nationalistische und royalistische Partisanengruppen setzten auf Druckmittel: In der Meldung des Chefs des Generalstabs des Militärbefehlshabers Südost von Geitner an die Heeresgruppe F vom 19. Februar 1944 wird etwa die „anhaltende Verschleppung und Mobilisierung durch DM [Draža Mihailović]- und Komm[unistische]-Banden“ erwähnt. ${ }^{130}$ Auf albanischer Seite griff auch der „Balli Kombëtar“ bereits seit Anfang 1943 zu Zwangsrekrutierungen, Schutzgeldforderungen und zur Requirierung von Lebensmitteln; und selbst die albanischen Kommunisten der „Nationalen Befreiungsfront“ führten Zwangsrekrutierungen unter Androhung drastischer Strafen durch. ${ }^{131}$

128 Ciano, Tagebücher, 3.6.1939, S. 100. Vgl. Zaugg, Albanische Muslime, S. 74-85. Vgl. zum Wunsch nach Autonomie auch Flugblatt angehängt an Reisebericht SS-Hauptsturmführer Hasan Bajralitarović[Bajraktarević] an Phleps, 15.11.1943, BArchB, NS19/2601, Bl. 61.

129 Vgl. hierzu ausführlich Personalakten im Arhiv Jugoslavije und in Prishtina/Priština: AJ F110 und Arkivi Kosoves, F: Dosjete robërve të luftës në Gjermani, V: 1940-1945, K: 1.

130 Chef des Generalstabs Militärbefehlshaber Südost, von Geitner an Heeresgruppe F, 19.2.1944, Bl. 92.

131 Vgl. Neuwirth, Widerstand und Kollaboration, S. 104, 116f., 199. Vgl. auch Meldung SSUntersturmführer Daca an Ia, 15.6.1944, BArchF, RS3-21/2, Bl. 95. 


\subsection{7 „Weltanschauliche Schulung“ und Islam}

„Weltanschauliche Schulung“ taucht zwar bei der „Prinz Eugen“ und der „Handschar“ in den Quellen auf, allerdings eher in Akten, die über die Planung Auskunft geben. Ob und in welchem Ausmaß ,weltanschauliche Schulung“ innerhalb der Truppe betrieben wurde, ist heute schwer nachvollziehbar. Dass etwa Wangemann, der die dafür zuständige Abteilung VI innerhalb der „Handschar“ leitete, aktiv war, indem er zahlreiche Blätter zu Vorgehensweisen verfasste und auch Kurse durchführte, lässt sich zwar belegen - Äußerungen ehemaliger Soldaten lassen aber darauf schließen, dass für solche „Schulungen“ im Divisionsalltag kaum Raum und Zeit war. ${ }^{132}$ Dass die „weltanschauliche“ Schulung nicht so umgesetzt wurde wie geplant, deuten auch Aussagen wie diejenige Schmidhubers vom Januar 1944 an, als er forderte, dass der neue Ersatz innerhalb der „Prinz Eugen“ intensiv „weltanschaulich“ geschult werden müsse. ${ }^{133}$

In drei der vier Divisionen lässt sich allerdings eine stringente anti-kommunistische Propaganda nachweisen, die darauf abzielte, bereits vorhandene Ängste zu schüren und den „Bolschewismus“ als eine traditions- und wertezersetzende Kraft erscheinen zu lassen. In den traditionsbewussten Gesellschaften Bosniens und Nord- bzw. „Neualbaniens“, sowie den ebenfalls traditionsverhafteten „volksdeutschen“ Gemeinschaften stieß eine solche Propaganda auf Gehör. Explizit nationalsozialistische Elemente finden sich hingegen kaum in diesen Flugschriften. ${ }^{134}$

Die anti-jüdische Propaganda tritt bei der Rekrutierung „Volksdeutscher“ in konkreterer Form auf als bei den muslimischen Divisionen. So wurde etwa verkündet, dass sich bereits während des Einmarschs der Deutschen im April 1941 Juden mit den Ungarn verbündet und diese dabei unterstützt hätten, „,volksdeutsche“ Besitzungen zu beschießen. ${ }^{135}$ Eine antisemitische Stoßrichtung als Teil einer antibolschewistischen, anti-britischen und anti-amerikanischen Propaganda kann auch für die „Handschar“ nachgewiesen werden. ${ }^{136}$

Einen wesentlichen Unterschied zwischen den vier Divisionen stellt der Umgang mit Religion innerhalb der Division „Handschar“ dar: Diese sollte exemplarisch als erste muslimische Waffen-SS-Division aufgestellt werden. Der Versuch, „weltanschauliche Schulung“ mit Islam zu kombinieren, wurde durchaus ernst genom-

132 Vgl. Bernwald, Muslime in der Waffen-SS, S. 41.

133 Vgl. Casagrande, Volksdeutsche SS-Division, S. 274.

134 Vgl. hierzu die Flugschriften in den einzelnen Kapiteln zu den Divisionen.

135 Vgl. Casagrande, Volksdeutsche SS-Division, S. $164 \mathrm{f}$.

136 Vgl. Entwurf Himmler, August 1943, BArchB, NS 19/2601, Bl. 148. 
men: Imame waren bis auf Bataillonsebene auf die Division verteilt. ${ }^{137}$ Die Inszenierung des Islam für die Waffen-SS blieb aber auf die „Handschar“ beschränkt, nicht zuletzt deswegen, weil im letzten Kriegsjahr, als die Aufstellungen für die „Skanderbeg“ und die „Kama“ anliefen, die Zeit für solche Propagandaaktionen fehlte. Der Stellenwert der Imame innerhalb der „Handschar“ war allerdings hoch. Dies zeigt sich auch daran, dass die muslimischen Geistlichen eine viel engere Bindung zur Division entwickelten und im Gegensatz zu ihren Kameraden oft bis zum Ende bei diesem Verband blieben. ${ }^{138}$

Mit der Einrichtung einer Großküche und etwa 15-20 Feldküchen sollte in der „Handschar“ auch bei der Verpflegung auf die „Einhaltung der muslimischen Riten“ Rücksicht genommen werden. ${ }^{139}$ In Prishtina/Priština und möglicherweise auch in anderen Orten wurden für die Division „Skanderbeg“ Kochlehrgänge für die muslimische Küche eingerichtet. ${ }^{140}$ Ob und wie sehr im Alltag darauf geachtet wurde, dass die Nahrung halāl war, kann heute nicht mehr nachvollzogen werden, denn spätestens ab Frühsommer 1944 herrschte gerade im Gebiet der „Skanderbeg“ eine extreme Nahrungsmittelknappheit. ${ }^{141}$ Dass muslimische Soldaten entsprechend ihren Essgewohnheiten verpflegt wurden, war aber keine Erfindung der Nationalsozialisten, sondern bereits von Österreich-Ungarn im Ersten Weltkrieg so gehandhabt worden. ${ }^{142}$ Aussagen Talbots von Pistor belegen außerdem, dass der Fastenmonat Ramadan auch in der „Skanderbeg“ eingehalten wurde, was manchmal mit Schwierigkeiten für die Ausbildung verbunden war, wie er sich erinnert. ${ }^{143}$

\subsubsection{Chancen und Grenzen von Multikultur innerhalb der Truppe}

Die Angehörigen deutscher Verbände in Südosteuropa stammten neben Bosnien, Kroatien, Albanien, Kosovo, Serbien, Rumänien, Ungarn, Deutschland und Österreich auch aus dem Elsass, Polen, der Slowakei, Italien, Bessarabien, Armenien,

137 Vgl. Sauberzweig, Divisions-Sonderbefehl „Betr: Stellung der Imame innerhalb der Division“, 13. SS-Division, Abt. VI Tgb.Nr. 21/44 geh., 8.3.1944, BArchB, NS 19/2601, Bl. 247.

138 Vgl. bspw. Ferhadbegović, Schuldig im Namen des Volkes, S. 3.

139 Vgl. Kriegsgefangenenbericht „Bericht über die 13. SS Division ,Handschar‘, ihre Aufstellung, Gliederung und 1. Einsätze im jugoslawischen Raum“, Walter Eipel, 14.11.1947, VA, HEM. OK.BOJCKA, 72-A/1-a/32, S. 3.

140 Vgl. Himmler an Berger, 22.7.1943, BArchB, NS 19/2601, Bl. 142. Vgl. auch von Pistor an Vopersal, ohne Datum, BArchF, N 756/182b.

141 Vgl. Zaugg, Albanische Muslime, S. 239-241.

142 Vgl. Pašić, Bosniaks in WWI: Loyal, Obedient, Different, S. 85-96.

143 Vgl. von Pistor an Vorpersal, undatiert, BArchF, N 756/182b. 
Russland und sogar der Schweiz. ${ }^{144}$ Von Beginn an stellten die unterschiedlichen Kulturen, aber auch die Mehrsprachigkeit in den Waffen-SS-Formationen, eine große Herausforderung dar. ${ }^{145}$ Diese tritt in den Quellen zu den drei Divisionen „Prinz Eugen“, „Handschar“ und „Skanderbeg“ vor allem in zwei Formen zutage: einerseits in der Festlegung der Kommando- und Ausbildungssprache und zweitens in Beschwerden über fremdsprachige Soldaten.

Selbst bei den „Volksdeutschen“, welche für die Division „Prinz Eugen“ rekrutiert worden waren, stellten deutsche Vorgesetzte fest, dass sie teilweise nur über spärliche Deutschkenntnisse verfügten. ${ }^{146}$ Theodor Eicke war sogar der Meinung, dass solche in „Fremdenbataillonen“ ganz besonders geschult und beobachtet werden sollten. Denn die Tatsache, dass sie weder Deutsch lesen noch schreiben konnten, machte sie in seinen Augen zu minderwertigen „Volksdeutschen“ ${ }^{147}$ In der „Handschar“ wurde als Kommandosprache Deutsch, als Ausbildungs- und Umgangssprache Bosnisch festgelegt. Für die „Skanderbeg“ gestaltete sich die Sprachregelung schwieriger: Dort wurde als Kommandosprache ebenfalls Deutsch, daneben aber auch Serbisch und Albanisch gesprochen. Viele der Albaner in der „Skanderbeg“ verstanden auch Serbisch und hatten teilweise selbst im jugoslawischen Heer gedient. Im besten Falle verstanden sie aus der Zeit der österreichischen Herrschaft auch ein paar Wörter Deutsch. Dennoch war im Falle der „Skanderbeg“ in noch stärkerem Maße als bei der bosnisch-kroatischen Division die Dolmetschertätigkeit zur Bewerkstelligung von Ausbildung und Alltag der Truppe wichtig. Wenn die Albaner kein Serbokroatisch verstanden, mussten Anweisungen zuerst von Deutsch auf Serbisch und danach von Serbisch auf Albanisch übersetzt werden. ${ }^{148}$ Andere Quellen berichten davon, dass in gewissen Rekrutierungszentren nur Türkisch oder Serbisch verstanden wurde, weil es den Albanern lange verboten war, ihre eigene Sprache zu sprechen. So schreibt auch

144 Vgl. Bericht Danilo Marchione, „Situazione militare delle truppe tedesche“, 5.11.1943, AUSSME, I3/b13/f1, S. 4. Vgl. Befragung Domenico Sivera, 15.5.1944, AUSSME, I3/b13/f1, S. 2. Etwa Hauptsturmführer Knapp, ursprünglich ein Schweizer Hauptmann, Kdr. einer Kompanie der „Skanderbeg“. Vgl. Alfons Zeitler an Vopersal, 7.11.1975, BArchF, N 756/182b, in: Zaugg, Albanische Muslime, S. 219.

$145 \mathrm{Zu}$ diesen Schwierigkeiten in allen drei bis dahin aufgestellten Divisionen äußerte sich Phleps gegenüber Himmler Anfang Mai 1944. Vgl. Schreiben Phleps an Himmler, 7.5.1944, BArchB, R9361-III/547576, S. 1.

146 Vgl. Casagrande, Volksdeutsche SS-Division, S. 184. Rgt. St. Qu. SS-Gebirgsjäger Regiment 2, August Schmidhuber, „Kroatische Volksdeutsche“, 29.8.1943, BArchB. NS 7/254. Bl. 1. Hier ist allerdings anzumerken, dass auch der Wortschatz und die Grammatik der deutschen bzw. „volksdeutschen“ Vorgesetzten mitunter zu wünschen übrig ließen.

147 Vgl. Casagrande, Volksdeutsche SS-Division, S. 184.

148 Vgl. Brief von Pistor an Vopersal, ohne Datum, BArchF, N 756/182b. 
Volkstumsreferent Dr. Feninger, dass in der Region um Mitrovica und Novi Pazar in den letzten beiden Jahrzehnten ,alles Albanische von den Serben schärfstens verfolgt worden“ war. ${ }^{149}$ Doch im Gegensatz zur kroatischen, bosnischen bzw. serbischen Sprache war bis Kriegsende kaum ein Deutscher fähig, Albanisch zu sprechen. ${ }^{150}$

Diese Sprachbarriere hatte nicht nur direkte Auswirkungen auf die Truppe, sondern prägte die deutsche Albanienpolitik im Allgemeinen. Laut dem Bericht zur „Entwicklung der militärischen Lage in Albanien im Herbst 1944“ ließen sich die Deutschen in ihren Entscheidungen oft von den albanischen Großgrundbesitzern und Clanchefs lenken, die vielfach Deutsch oder „eine andere Weltsprache fließend beherrschten. Dagegen war das Herankommen an das eigentliche Volk und damit das Erkennen der in der breiten Masse vorhandenen Unterströmungen sprachlich sehr erschwert.“151

Mit Vorliebe wurden für Führer- und Unterführerränge Männer genommen, welche bereits Erfahrungen in Südosteuropa gesammelt hatten oder durch ihre Herkunft mit der Region verbunden waren. Dieses Vorgehen kann für alle Divisionen nachgewiesen werden und ist eine Tradition, die in die österreichischungarische Epoche zurückreicht, wie Tamara Scheer feststellt. ${ }^{152}$

Ideal war Führungspersonal, das sich durch seine Sprachkenntnisse mit allen Beteiligten direkt unterhalten konnte, beispielsweise Richard Kaaserer, Karl von Krempler oder Desiderius Hampel. ${ }^{153}$ Gerade „Volksdeutsche“ aus Südost- bzw.

149 Vgl. Bericht „über die Reise in das Arnautengebiet von Kosovska Mitrovica und Novi Pazar“ des Volkstumsreferenten Dr. Feninger beim Bevollmächtigten des AA in Belgrad, 15.-26.10.1941, PAAA, R261153, Bl. 37. Vgl. Schreiben Phleps an Himmler, 7.5.1944, BArchB, NS 19/2601, Bl. 95. Vgl. Brief von Pistor an Vopersal, ohne Datum, BArchF, N 756/182b.

150 Rudolf Vogel, späterer Präsident der Südosteuropa-Gesellschaft (SOG), war während des Krieges in Albanien stationiert und hebt in seinen Erinnerungen die Wichtigkeit von Übersetzern hervor. Vgl. Zaugg, „Unter Skipetaren“ - Die deutsche Besatzungszeit in Albanien, in: Südosteuropa Mitteilungen 3/4 (2015), S. 109. Dass solche sprachlichen Schwierigkeiten nicht nur bei den südosteuropäischen Waffen-SS-Verbänden, sondern auch andernorts, beispielsweise im Kaukausus, auftraten, erwähnt Ruth Bettina Birn. Sie bezweifelt den Wert solcher Einheiten und ob solche überhaupt noch zur Stärkung der deutschen Kampfkraft beitrugen, wenn bereits die sprachliche Verständigung scheiterte. Vgl. Birn, SS-Ideologie und Herrschaftsausübung, S. 61.

151 OB Südost, Bericht „Entwicklung der militärischen Lage in Albanien im Herbst 1944“, undatiert, BArchF, RW40/116a, Bl. 12.

152 Scheer, A Reason to Break the Haag Convention?, S. 1013.

153 Vgl. Himmler an Chef SS-Personalamt, 14.5.1944, Personalakte Richard Kaaserer, geb. 21.8.1896, BArchB, ehemals BDC. Vgl. Berger an Himmler, „Betr.: Bosniaken-Division“, 29.4.1943, BArchB, NS 19/2601, Bl. 11. Vgl. Werhas, Mikulčić, „Handschar”, „Skanderbeg“, „Kama“, S. 19. 
Osteuropa wurden, da sie eine oder mehrere slawische Sprachen beherrschten, als Dolmetscher und/oder Führungspersonal in den untersuchten muslimischen Verbänden eingesetzt. ${ }^{154}$ Da sie mit den Mannschaften kommunizieren konnten, hoffte die SS-Führung, durch sie die südosteuropäischen Divisionsangehörigen kontrollieren zu können.

Neben der Sprache boten der Umgang mit Religion, aber auch kulturelle Unterschiede oft Anlass zu Auseinandersetzungen etwa zwischen Bosniern und Albanern oder auch zwischen muslimischen und katholischen Divisionsangehörigen der „Handschar““ ${ }^{155}$ Selbst ein anderer Sinn für Humor konnte einen Stein des Anstoßes bilden, daher sollten deutsche Vorgesetzte darauf gerade im Umgang mit Albanern besondere Rücksicht nehmen; ${ }^{156}$ und Himmler verbot allgemein jedes Witzeln gegenüber muslimischen Soldaten. ${ }^{157}$

Solche Anweisungen dürfen aber nicht darüber hinwegtäuschen, dass in allen hier vorgestellten Divisionen der Umgang mit Soldaten anderer Nationen, wie an einigen Beispielen gezeigt, oft von alltäglichem Rassismus geprägt war. ${ }^{158}$ Unüberlegte, herablassende Handlungen und Bestrafungen hatten manchmal unangenehme Folgen: So gab SS-Sturmbannführer Wolfgang Wetzling am 3. Juli 1943 in Sarajevo dem Goldschmied Condrc eine Ohrfeige, weil er glaubte, dieser hätte versucht, den Stein aus der Fassung eines zu reparierenden Rings zu lösen. Himmler wurde dieser wie auch andere Vorfälle der SS gegen Muslime gemeldet, und er ließ sie - da letztere nun als wichtige Verbündete galten - sofort untersuchen. Phleps musste nach Abschluss der Untersuchung eingestehen, dass „Stubaf. Wetzling [...] in diesem Falle einen großen Fehler begangen [habe], da ein Muselmane durch eine Ohrfeige mehr gekränkt ist als ein anderer Mensch. Er gibt an, diese Mentalität nicht gekannt zu haben.“159

154 Ein solcher Bericht über eine „volksdeutsche“ Dolmetscherlaufbahn bei der Division „Handschar“ findet sich beispielsweise bei Bernwald, Muslime, S. $43 \mathrm{f}$.

155 Vgl. Deutsches Konsulat Sarajevo, Erich Gördes an Deutsche Gesandtschaft Agram, 23.8.1943, PAAA Inland IIg R100998. Vgl. Rochas, La Handschar, S. 77.

156 Vgl. Kaesdorf, „Erfahrungen mit albanischen Soldaten“, undatiert, BArchB, NS 31/444, S. 28.

157 Vgl. Entwurf Himmler, August 1943, BArchB, NS 19/2601, Bl. 148.

$158 \mathrm{Vgl}$. bspw. Casagrande, Südtiroler in der Waffen-SS, S. $39 \mathrm{f}$.

159 Phleps an Reichsführer SS Himmler, 7.9.1943, BarchB, NS19/1434, Bl. 16. 


\subsubsection{Deutsche Soldaten vor Ort und ihr Verhältnis zur Bevölkerung}

Der ehemalige Major Hermann K. Frank berichtet, dass er sich während seines Einsatzes in Südosteuropa „zu keiner Zeit und nirgends“ sicher fühlte. Er beschreibt seine und die Situation seiner Soldaten in Albanien als „praktisch machtlos“. ${ }^{160}$ Borkowsky charakterisiert die Kriegführung aus seiner Sicht noch zwanzig Jahre später mit folgenden Worten: „Die Situation des Partisanenkrieges auf dem Balkan war grausam. Von den Partisanen wurden grundsätzlich keine Gefangenen auch keine Verwundeten gemacht. Es ging tatsächlich im Partisanenkrieg um Sein oder Nichtsein.“161 In diesen Worten kommt der enorme psychische Druck zum Ausdruck, dem die in Südosteuropa, inmitten dieser unübersichtlichen, komplexen Konflikte verschiedenster Bürgerkriegsparteien stationierten deutschen Einheiten ausgesetzt waren. ${ }^{162}$

Oft fühlten sich die Deutschen eher in der Rolle der Verfolgten, denn als der Besatzer, wie zahlreiche Dokumente belegen. Diese Gefühlswelt aus Angst und Unsicherheit bildete auch die mentale Grundlage der in Südosteuropa stationierten Waffen-SS-Angehörigen. Trotz radikaler Sühnemaßnahmen, 1:50 oder 1:100 für einen verwundeten bzw. einen getöteten deutschen Soldaten, flaute der Widerstand nicht ab, sondern nahm, im Gegenteil, seit 1943 exponentiell zu. Auch nach der italienischen Kapitulation im September 1943 erschossen vorrückende deutsche Truppen jeden, den sie fanden, ohne Gnade und ohne Unterscheidung; die meisten Opfer starben „ohne jegliche Schuld“, wie italienische Quellen dokumentieren. Familien boten den deutschen Soldaten Nahrung an, um so zu verhindern, dass diese ihr Haus niederbrannten. ${ }^{163}$

Obwohl große Teile der Bevölkerung bis zum Balkanfeldzug, wie oben gezeigt, ein durchaus positives Bild von den Deutschen gehabt hatten, führte dieses brutale Vorgehen dazu, dass sie sich von den Deutschen abwandten, weil solche Vergeltungsmaßnahmen zu viele Unschuldige trafen und die deutschen Besatzer gleichzeitig weder Plünderungen noch Massaker durch andere Banden verhindern konnten, mehr noch, untätig zuschauten, wie „die deutschfreundliche Bevölkerung abgeschlachtet wurde“, so der Vorwurf. ${ }^{164}$

160 Frank, Partisanenkampf in Albanien, S. 360. Vgl. ebd. 358 f.

161 Vgl. Fall Günter Borkwosky, Aussage Günter Borkowsky, 26.8.1963, USHMM, BArchL, B 162/20812, Bl. 10.

162 Vgl. Frank, Partisanenkampf in Albanien, S. 358.

163 Bericht Sottotenente Moncalvo, 21.9.1943, AUSSME, I3/b13/f1, S. 1.

164 Vgl. Nedim Salihbegovic, „Bericht zur Lage“, 25.9.1943, BArchB, NS 19/2601, Bl. 29-31. 
Ein Schreiben der Abteilung Ic des Generalkommandos des LXIX. Reservekorps veranschaulicht dieses Dilemma, in welchem sich die deutschen Einheiten auf dem Balkan im letzten Kriegsjahr befanden:

„Betr.: Zivilbevölkerung im Bandengebiet

Das zweifellos schwierigste Problem im kroatischen Bandengebiet ist für die Truppe das Verhalten zur Zivilbevölkerung.

In dem eben erst von Banden befreiten Gebiet können alle Arten von Zivilisten vorkommen: vom durchtriebenen, als Zivilisten getarnten Banditen, der eben noch gegen unsere Truppe gekämpft hat, bis zum tatsächlich unschuldigen Zivilisten, der vielleicht gerade erst aus seinem Versteck vor den Banden herauskam, tritt alles an unsere Soldaten heran und beteuert die Unschuld oder bietet sogar Mitarbeit an.

[...] Ein infolge anfänglicher Ungerechtigkeit verbitterter Zivilist ist und bleibt meist für immer ein Gegner.

[...] In jenen Orten, wo alles als Feind anzusehen ist, wird dies nach eingehender Prüfung durch die Führung befohlen werden. Gerade hier müssen die zu treffenden Maßnahmen genau festgelegt werden. In diesem Falle werden wohl vorerst alle Zivilisten festzunehmen sein und erst spätere Überprüfung wird ergeben, wer in Haft bleibt oder als Geisel gilt und wer als unschuldig oder aufbauwillig wieder zu entlassen ist.“165

Trotz der oben genannten „Sühnekontingente“ von 1:50 und 1:100 in der Zeit von 1941 bis Ende 1943 gelang es den Deutschen nicht, ihre Macht über die Zentren hinaus auszudehnen und die als bedrohlich wahrgenommene Umgebung unter Kontrolle zu bringen. Zahlreiche schwer zugängliche ländliche Gebiete und Bergregionen Südosteuropas blieben in der Hand der verschiedenen kommunistischen und anderer Widerstandgruppen. ${ }^{166}$ Aufgrund ausbleibender Erfolge ließ der stellvertretende OB Südost, Generaloberst Alexander Löhr, in einem Schreiben vom 22. Dezember 1943 die „Sühnemaßnahmen“ schließlich anpassen, deren erster Grundsatz nun war, den Täter selbst zu fassen und „Sühnemaßnahmen“ erst dann zu ergreifen, wenn mit weiteren Anschlägen zu rechnen war - was immer noch einen immensen Spielraum für die Kommandeure offen ließ. ${ }^{167}$

Entsprechend jener unsicheren Situation, in der sie sich befanden, erreichte die Moral deutscher Truppen in Südosteuropa Ende 1943/Anfang 1944 einen

165 Gen.Kdo.LXIX.Res.Korps, Abt. Ic, 11.1.1944, BArchF, RS 3-8/92, Bl. 0006.

166 Vgl. Befragung Guido Tecchi 24.10.1943, AUSSME, I3/b13/f1.

167 Vgl. OB Südost i.V., Generaloberst Alexander Löhr, Abschrift „Sühnemaßnahmen“, 22.12.1943, BArchF, RW 40/89, S. 1, 3. Vgl. hierzu auch Weisung „Sühnemaßnahmen“ OB Südost i.V. Generaloberst Alexander Löhr, 22.12.1943, BArchF, RW 40/89. 
Tiefpunkt. Italienische Quellen berichten, dass sich die in deutschen Reihen kämpfenden Soldaten fast allabendlich betrinken und dann schreien würden: „Es lebe Stalin! Es lebe Churchill! Wir sind Engländer! Hitler [ist] kaputt!“168 Weiter sagten italienische Rückkehrer bei ihrer Befragung aus: „Die Moral innerhalb der deutschen Truppen vor allem in den besetzten Gebieten ist nicht sehr hoch und es besteht die feste Überzeugung über einen negativen Ausgang des Krieges. Bei gewissen Teilen der unverkennbar deutschen Abteilungen ist die Moral noch hoch und sie glauben treu dem Wort Hitlers."169 Oder auch: „Die Moral und die Disziplin der deutschen Truppen sind stark im Rückgang; Fälle von Korruption, dem Verkauf von Waffen, Ungehorsam und exzessiver Nervosität, moralischer und materieller Müdigkeit.“170

An anderer Stelle ist zu lesen:

Das deutsche Heer ist nicht mehr das, was es mal war, weder bezüglich der Disziplin noch bezüglich der Moral. Viele Offiziere (Österreicher) lassen sich mit Geld bestechen, wenn es darum geht, die Flucht [ehemaliger italienischer Soldaten aus Südosteuropa] mithilfe italienischer Boote zu erlauben. [...] Zahlreich sind Disziplinarfälle (Betrunkenheit, Ungehorsam, Verkauf von Waffen und Material), von denen wir Zeuge werden konnten. [...] Insbesondere die jüngsten Jahrgänge [19](25-26) zeigen Müdigkeit und keine Bereitschaft, die Mühen zu ertragen. ${ }^{171}$

In der unübersichtlichen, zuweilen chaotischen Situation, in der sich die deutschen Truppen im Südostraum seit 1941 befanden, waren auch die Kommandeure der Waffen-SS-Divisionen oft auf sich gestellt und gezwungen, etwa bei den Rekrutierungen, in unüblicher Weise vorzugehen. Sowohl Phleps als auch Schmidhuber mussten sich teilweise selbst um die Rekrutierungen kümmern: Phleps sollte bei seinen Bekannten des ehemaligen k.u.k. Offizierkorps requirieren, Schmidhuber hingegen musste Werbereden auf den Markplätzen im Kosovo halten. ${ }^{172}$

168 „Situazione politica-militare dell'Albania a tutto, il 19 ottobre 1943“, AUSSME, I3/b13/f1, S. 2. 169 „Il morale delle truppe tedesche, specie quelle di territori annessi, non molto elevato e ferma convinzione dell'esito negativo della guerra. Fra componenti invece i reparti di spiccata marca tedesca morale ancora alto e ligi e credenti al verbo Hitleriano.“ Bericht 8.-15.9.1943, AUSSME, I3/b13/f1, S. 2.

170 „il morale e la disciplina delle truppe tedesche sono in forte ribasso; casi di corruzione, die vendita di armi, di indisciplina, die eccessivo nervosismo, di stanchezza morale e materiale." Situazione Albania, 10.10.1943, AUSSME, I3/b13/f1, S. 3.

171 Befragung Cpt. Renato Predome und Ten. Giorgio Cortese, 10.10.1943, AUSSME, I3/b13/f1, S. 2. Ähnliche Aussagen finden sich auch im Lagebericht 7.4.-15.6.1944, IX. Waffen- (Gebirgs-) A.K. der SS, Ic 31/44/108/ g. Kdos., 15.6.1944, PAAA, R 101095.

172 Vgl. Kumm, Vorwärts Prinz Eugen, S. 27. Vgl. Schmidhuber, „Zusammenfassender Bericht“, 2.10.1944, BArchF, RS 3-21/1, S. 3. Vgl. Bericht der Polizeidirektion des Kreises Prizren vom Mai 1944, A.Q.SH. F.153, 1944, D 141, Bl. 11. Beide Divisionskommandeure hätten eigent- 
Entsprechend der Kriegssituation veränderte sich auch das Bild, welches die Deutschen von ihren „volksdeutschen“ bzw. „fremdvölkischen“ Untergebenen hatten: Vor der Rekrutierung wurden die Bevölkerungsgruppen, welche im Visier der SS-Werber waren, hinsichtlich ihrer „rassischen“ Abstammung und der sich vermeintlich daraus ergebenden kriegerischen Eigenschaften, als auch in ihrem Verhältnis zum NS System durchaus positiv dargestellt. ${ }^{173}$ Nach ersten Kontakten, der Ausbildungszeit und ersten Einsätzen veränderte sich allerdings das Bild der Deutschen stark: Nun wurden sowohl „Volksdeutsche“ als auch Muslime mit negativen Eigenschaften belegt. Ein sehr frühes derartiges Zeugnis ist Eickes Beschreibung von „Volksdeutschen“ vom 15. November 1941, in der er sie als oft minderwertig und mit einem Hang zur Selbstverstümmelung und Feigheit schilderte. ${ }^{174}$

Sehr ähnlich klingt es, wenn Erich Gördes nach Agram meldet, die bosnischen Muslime seien faul und streitsüchtig. Um dem Dienst zu entgehen, würden sie sich Körperteile mit Sand wund reiben oder sich am Körper durch das Schlagen mit einer Bürste selbst Verletzungen zufügen. ${ }^{175}$ Die Albaner kamen indessen nicht besser weg: Schmidhuber etwa schrieb, dass „der Heldenmut des Albaners“ reine Erfindung sei und der albanische Soldat im Angriff nur soweit gehen würden, bis er etwas erbeutet hätte. ${ }^{176}$ Außerdem seien die Albaner ängstlich und schreckhaft. ${ }^{177} \mathrm{Zu}$ diesem Schluss kam auch HSSPF Albanien, Fitzthum, der berichtete, dass der „albanische[...] Soldat undiszipliniert und feige“ sei und entweder desertieren oder „vor Angst Notdurft in die Hose“ machen würde. ${ }^{178}$

lich auch die militärische Infrastruktur ihrer Vorgänger, etwa von Italienern oder gar aus österreichisch-ungarischer Zeit, übernehmen sollen, mussten aber feststellen, dass sich beispielweise die Truppenunterkünfte in einem so schlechtem Zustand befanden, dass sie diese zuerst wiederaufbauen lassen mussten. Vgl. Kumm, Vorwärts Prinz Eugen, S. 38. Vgl. Schmidhuber, „Zusammenfassender Bericht“, 2.10.1944, BArchF, RS 3-21/1, S. 4.

173 Vgl. etwa Kaesdorf, „Erfahrungen mit albanischen Soldaten“, undatiert, BArchB, NS 31/ 444, Bl. 27. Neubacher, Sonderauftrag Südost, S. 33, 108. Vgl. Bericht Donauzeitung „Im Geiste Skanderbegs“ von Dr. K., 26.7.1944, ASD, RSI, Aff. Pol., Busta, 51. Janko, Einteilung der Volksdeutschen in Banat und Serbien, BArchB, NS19/2601, zitiert nach Casagrande, Volksdeutsche SS-Division, S. 181.

174 Vgl. Schreiben Eicke, SS-Kraftfahrer, Ausbildungs- und Ersatzrgt., Archiv Prag, Karton 1,4/kr.1. Nach: Casagrande, Volksdeutsche SS-Division, S. 184.

175 Vgl. Deutsches Konsulat Sarajevo, Erich Gördes an Deutsche Gesandtschaft Agram, 23.8.1943, PAAA Inland IIg R100998.

176 „Zusammenfassender Bericht“ Schmidhuber, 2.10.1944, BArchF, RS 3-21/1, S. 2.

177 Vgl. ebd.

178 Fitzthum an Himmler über den Zustand albanischer Verbände, 23.5.1944, BArchB, NS 19/2071, Bl. 14. 


\subsubsection{Die Größe der Divisionen, ihr Ausbildungsgrad und Kampfwert}

Die Größe der Divisionen unterschied sich stark: So kann bei der „Prinz Eugen“ oder der „Handschar“ mit rund 21.000 Mann von vollwertigen Divisionen gesprochen werden. ${ }^{179}$ Die Divisionen „Skanderbeg“ und „Kama“ hingegen erreichten mit 8.500 respektive 3.600-8.000 Mann nicht einmal annähernd ihre Sollstärke. ${ }^{180}$ Auch die Ausbildungszeit bzw. der Ausbildungsgrad der einzelnen Divisionen war sehr unterschiedlich: Teilweise durchliefen Soldaten innerhalb der „Prinz Eugen“ und „Handschar“ eine intensive Ausbildung, andere wiederum absolvierten nur einen wenige Wochen dauernden Lehrgang. ${ }^{181}$ Eine Besonderheit der Division „Handschar“ war außerdem, dass die Angehörigen ihre Ausbildungszeit größtenteils im Ausland, in Le Puy und Villefranche-de-Rouergue in Frankreich und Neuhammer in Schlesien verbrachten. ${ }^{182}$ In der „Skanderbeg“ teilten sich die Soldaten in drei Gruppen: einerseits die bereits kampferprobten Albaner aus der Division „Handschar“, die aus deutscher Kriegsgefangenschaft entlassenen ehemaligen Soldaten der jugoslawischen Armee und die zahlreichen neuen Rekruten, die teilweise nach nur sechswöchiger Ausbildung in den Kampf geschickt wurden. ${ }^{183}$ Zur „Kama“ sind leider bezüglich der Art der Ausbildung keine näheren Angaben zu machen.

Auch die Menge und die Qualität der Ausrüstung unterschied sich stark. Diese Unterschiede verliefen aber nicht etwa entlang der Linie „,volksdeutsche“/,fremdvölkische“ Division, sondern ergaben sich vielmehr aufgrund des Zeitpunkts der jeweiligen Aufstellung. Für die ersten beiden Balkan-Divisionen standen trotz der Niederlagen an der Ostfront weitaus mehr Ressourcen zur Verfügung als für die erst 1944 aufgestellten Verbände „Skanderbeg“ und „Kama“. ${ }^{184}$ Große Teile der Ausrüstung wurden aus - vor allem italienischen - Beutebeständen zusammengestellt. ${ }^{185}$ Doch bereits im Oktober 1943 meinte der Leiter des Referats VIa, Wal-

179 Vgl. Petke, Muslime in der Waffen-SS, S. 1. Von einem Soll von rund 21.600 Mann erreichte die „Handschar“ im April 1944 21.000 Mann. Vgl. Stärkemeldung „Handschar“, 17.4.1944, BArchB, NS19/1475, Bl. 6. Von einem Soll von rund 27.600 Mann erreichte die „Prinz Eugen“ im April 1944 21.500 Mann. Vgl. Stärkemeldung „Prinz Eugen“, 17.4.1944, BArchB, NS 19/1475, Bl. 6.

180 Die Sollstärke beider Divisionen lag bei 19.000 Mann. Vgl. Stärkemeldung „Skanderbeg“ und Stärkemeldung „Kama“, 5.9.1944, BArchB, NS19/1475, Bl. 13. Vgl. auch Klietmann, Waffen-SS: eine Dokumentation, S. 243.

181 Vgl. Milata, Zwischen Hitler, Stalin und Antonescu, S. 244.

182 Vgl. Zaugg, Albanische Muslime, S. 190.

183 Vgl. ebd., S. 249.

184 Vgl. bspw. Schmidhuber, „Zusammenfassender Bericht“, 2.10.1944, BArchF, RS 3-21/1, S. 5.

185 Vgl. Schreiben Berger an das AA, z.Hd. Reichel, 11.10.1943, BArchB, NS 19/1660, Bl 4. 
ter Letsch: Dass zur Ausrüstung der neu aufgestellten Verbände in Südosteuropa überhaupt Waffen zur Verfügung stünden, müsse bereits positiv gewertet werden. $^{186}$

Entsprechend ihrer Ausbildungszeit, dem Grad ihrer Ausrüstung, der Motivation der Soldaten, der Qualität der Führer und Unterführer, der jeweiligen Versorgungslage sowie dem Zeitpunkt und den topographischen Besonderheiten ihrer Einsätze unterschied sich auch der Kampfwert der vier Divisionen. Während die „Prinz Eugen“ als „Balkan-Feuerwehr“ bezeichnet wurde und die Division „Handschar“ zeitweise ganz Ost-Bosnien unter ihrer Kontrolle hatte, gerieten die spärlichen Einsätze der „Skanderbeg“ und „Kama“ aufgrund unzureichender Bewaffnung und Ausbildung zum Desaster. ${ }^{187}$ Bei allen vier Divisionen bestanden zunehmend prekäre Personalengpässe, wie Phleps im Mai 1944 gegenüber Himmler betonte: Obwohl bereits zu diesem Zeitpunkt offensichtlich war, dass die Aufstellung der „Skanderbeg“ mit dem vorhandenen Rahmenpersonal nicht gelingen würde, konnte er weder aus der Division „Handschar“ noch der „Prinz Eugen“ Ausbilder entbehren. Letztere wies zu diesem Zeitpunkt selbst weniger als 50 Prozent der nötigen Führer und Unterführer auf. ${ }^{188}$

\subsubsection{Kriegführung, Ungehorsam, Aufstände und Desertionen}

Das Gefälle hinsichtlich des Ausbildungsgrads wie auch das Verständnis von moderner Kriegführung verlief entlang der Grenze der ehemaligen österreichischungarischen Herrschaft: Wer von den rekrutierten „Volksdeutschen“ bzw. Bosniern, Albanern und Kroaten bereits in der österreichisch-ungarischen und/oder der jugoslawischen bzw. der rumänischen Armee gedient hatte, konnte sich eher ein Bild davon machen, was ihn erwartete. Teile der rekrutierten Albaner und Bosnier hingegen waren noch in einem Verständnis von Kriegführung verhaftet, bei welchem sich der Soldat im Nahkampf auszeichnete, Fernkampf aber, etwa durch Artilleriebeschuss, verstörend und furchteinflößend wirkte. Außerdem galt Plündern als übliches Mittel, um seinen Sold aufzubessern und Krieg gegen den lokalen Gegner wurde ohne Erbarmen auch gegen Frauen und Kinder geführt. ${ }^{189}$

186 Vgl. Schreiben Letsch an Berger, 8.10.1943, BArchB, NS 19/1660, Bl 2.

187 Vgl. Gen.Kdo. XXI. Geb.A.K., von Leyser an „Skanderbeg“, 25.8.1944, NARA, T314/664, F. 594. Vgl. Stab „Skanderbeg“ Ia an Hstuf. Bormann, 15.6.1944, BArchF, RS 3-21/2, S. 10. Vgl. Meldekopf Rožaje, Hoffmann an Bendl, 11.7.1944, BArchF, RS 3-21/2, S. 15.

188 Vgl. Schreiben Phleps an Himmler, 7.5.1944, BArchB, R9361-III/547576, S. 1.

189 Vgl. Bericht Ic, Unternehmen „Berane“, 19.10.1943, BArchF, RH 26-297/106, S. 3. 
Auffallend ist die Anzahl an Aufständen, Befehlsverweigerung und kollektivem Ungehorsam bzw. kollektiver Desertion in diesen vier Divisionen. Die heute bekannteste ist die Meuterei der Division „Handschar“ während ihrer Ausbildung in Südfrankreich im September 1943. ${ }^{190}$ Im Herbst 1944 kam es aber sowohl innerhalb der „Handschar“ als auch ihrer Schwesterdivision „Kama“ zu zwei weiteren Aufständen. In der „Prinz Eugen“ ist unter anderem eine kollektive Befehlsverweigerung von 173 Divisionsangehörigen dokumentiert und in der Division „Skanderbeg“ desertierten auf einen Schlag 1.000 Mann. Hinzu kam, dass viele der aus Gefangenschaft oder Kriegsgefangenschaft Entlassenen auf dem Weg zur Division in die Wälder oder in ihre Dörfer verschwanden und dem Marschbefehl keine Folge leisteten. ${ }^{191}$

\subsubsection{Verfolgung ehemaliger Waffen-SS-Angehöriger der „Prinz Eugen“, „Handschar“, „Skanderbeg“ und „Kama“}

Die meisten Bosnier und Albaner wurden im September und Oktober 1944 aus den sich auflösenden Divisionen entlassen, nach Hause geschickt und ihrem Schicksal überlassen. Viele gingen für die letzten Monate oder Wochen zu den Partisanen, da sowohl Tito als auch Hoxha im September Amnestieversprechen für Überläufer abgegeben hatten. ${ }^{192}$ Einige blieben aber bis zum Ende des Krieges in ihren Einheiten. Dies gilt in besonderem Maße für Soldaten mit speziellen Aufgaben, wie Imame, aber auch Pferdepfleger und Übersetzer. ${ }^{193}$ Auch von den „Volksdeutschen“ verblieben viele in ihren Divisionen, da sie weder zurück in ihre Heimatgebiete noch sich überwinden konnten, sich den Partisanen anzuschließen. ${ }^{194}$

Wenn die Soldaten bei Kriegsende in jugoslawische Gefangenschaft gerieten, wurden sie oft erschossen, Schluchten hinuntergestürzt oder aber zu Haftstrafen und Arbeitslager verurteilt. Solche, die nach Hause zurückgekehrt waren, ohne sich vorher einer kommunistischen Partisanengruppe angeschlossen $\mathrm{zu}$ haben, wurden später teilweise mit Berufsverbot belegt oder zur Auswanderung gezwungen. ${ }^{195}$ Hinsichtlich der Verfolgung ehemaliger „Handschar“-Veteranen in der Föderati-

190 Vgl. ausführlich: Grmek, Lambrichs, Les révoltés.

191 „Zusammenfassender Bericht“ Schmidhuber, 2.10.1944, BArchF, RS 3-21/1, S. 7. Vgl. Interview mit Tush Mark Ndou (geführt von Franziska Zaugg), 7.6.2017.

192 Tito hatte bis zum 15. September 1944 ein Amnestieversprechen für alle Überläufer ausgegeben, die albanischen Kommunisten versprachen ebenfalls Straffreiheit für all jene, die bis am 22. September überlaufen würden. Vgl. Zaugg, Albanische Muslime, S. 281.

193 Vgl. Zaugg, Albanische Muslime, S. 277. Vgl. Ferhadbegović, Schuldig, im Namen des Volkes, S. 3. Vgl. Werhas, Mikulčić, „Handschar”, „Skanderbeg“, „Kama“, S. 49.

194 Vgl. Casagrande, Volksdeutsche SS-Division, S. 247.

195 Vgl. Zaugg, Albanische Muslime, S. 285. 
ven Volksrepublik Jugoslawien lassen sich vier Phasen erkennen: Die erste Phase war gekennzeichnet von oft spontaner, nicht vom Staat angeordneter aber durchaus tolerierter Gewalt bei Kriegsende 1945 und in den ersten Monaten danach. Böhme schreibt, dass in dieser ersten Zeit zahlreiche Verstöße gegen das Kriegsvölkerrecht stattgefunden hätten, einerseits verübt von Partisaneneinheiten im Siegesrausch und aus Rachegelüsten, andererseits aber auch, weil diese mit der Aufgabe, plötzlich so viele Kriegsgefangene verwalten $\mathrm{zu}$ müssen, überfordert waren. Es kam zur Erschießung Zehntausender ohne Gerichtsverfahren. ${ }^{196}$

In einer zweiten Phase waren die Urteile gegenüber diesen so genannten „Verführten“ noch von der Unerbittlichkeit des Bürgerkriegs geprägt. Eine dritte Phase, die durch ein abnehmendes Interesse an Vergeltung Ende der 1940er Jahre eingeleitet wurde, zeichnete ein höheres Maß an Toleranz aus. Nur diejenigen, die bis zuletzt die deutschen Besatzer oder nationalistische Gruppierungen unterstützt hatten, wurden weiterhin verfolgt. ${ }^{197}$ Tito unterstützte in dieser dritten Phase ein Zusammenwachsen der verschiedenen Bevölkerungsgruppen Jugoslawiens. Er leitete schließlich eine vierte und letzte Phase ein, die durch verordnetes Schweigen helfen sollte, die Erinnerung an den Zweiten Weltkrieg zu überwinden. ${ }^{198}$

Besonders betroffen von Gewalt und Massenerschießungen waren bei Kriegsende in Südosteuropa Angehörige der Waffen-SS-Divisionen, „Handschar“ und „Prinz Eugen“, der Polizei, Gendarmerie und ein Teil der Offiziere, die im slowenischen Grenzgebiet in Gefangenschaft gerieten. ${ }^{199}$ Böhme dokumentiert in seiner Zusammenstellung kleinere und größeren Massenerschießungen am Ende des Krieges, von Mai bis in die Sommermonate des Jahres 1945: So wurden etwa am rechten Save-Ufer bei Brestanica/Reichenburg am Pfingstsonntag 1945450

196 K.W. Böhme (Maschke, Erich, Hg.), Zur Geschichte der deutschen Kriegsgefangenen des Zweiten Weltkriegs, Bd. I/1, München: Gieseking 1962, S. 102, 108. Ehemalige Angehörige der Waffen-SS zitieren in apologetischen Schriften immer wieder Artikel 2 der Genfer Konvention. Vgl. etwa „Titos Taten“, in: Nation Europa. Monatsschrift im Dienste der europäischen Erneuerung, XII Jhg. 4(1962), S. 23-28. Vgl. Zur einseitigen Darstellung bspw. von Bleiburg auch Michael Portmann, Communist Retaliation and Persecution on Yugoslav Territory during and after WWIl (1943-1950), Tokovi istorije 1-2(2004), S. 47. Zum Schicksal der Angehöriger verschiedener militärischer Einheiten und von Zivilisten, die versuchten nach Westeuropa zu gelangen: Vgl. ebd., S. 68-70.

197 Vgl. Ferhadbegović, Vor Gericht, S. 243, 249.

198 Assmann beschreibt in Bezug auf die westdeutsche Nachkriegsgesellschaft, was auch für Jugoslawien Geltung hat: Das kommunikative Beschweigen habe den Rückzug aus der politischen Öffentlichkeit ermöglicht und die nahe Vergangenheit aus dem gesellschaftlichen Bewusstsein verschwinden lassen. Die Auseinandersetzung habe man dem „Sickerschacht“ der privaten Bewältigung überlassen. Vgl. Assmann, Aleida, Der lange Schatten der Vergangenheit, Erinnerungskuktur und Geschichtspolitik, München: C.H. Beck 2014², S. 179.

199 Böhme, Geschichte der deutschen Kriegsgefangenen, S. 107. 
Mann, immer sechs mit Telefondraht aneinandergefesselt, durch Genickschuss hingerichtet. 300 weitere im Bach erschossene Soldaten wurden in ein nicht näher genanntes Sammelgrab umgebettet. ${ }^{200}$

Aus den Grenzzonen wurden von deutscher Seite Rückführungen durchgeführt, in Berlin wurde schon im Dezember 1944 eine „Zentralauskunftsstelle für Rückgeführte“ eingerichtet. Darunter befanden sich auch aufgeführt in einer separaten Liste SS-Angehörige aus dem Südostraum. ${ }^{201}$ SS-Soldaten verschiedener Verbände versuchten von ihren letzten Einsatzorten, beispielsweise Brod, Zagreb oder Sarajevo weiter Richtung Westeuropa zu fliehen, um einer jugoslawischen oder sowjetischen Kriegsgefangenschaft zu entgehen. Dabei wurden sie nicht selten Opfer spontaner Gewalteskalationen. ${ }^{202}$ Bernwald schreibt rückblickend, jeder habe gewusst, dass er in Kriegsgefangenschaft der Westalliierten bessere Überlebenschancen hätte als in einem jugoslawischen oder russischen Kriegsgefangenenlager. Oft waren es aber intuitive Entscheidungen, die entweder in die eine oder andere Kriegsgefangenschaft führten, denn meistens bestanden nur vage Vermutungen, wo die westliche Besatzungszone beginnen würde; sichere Hinweise gab es kaum. ${ }^{203}$

Allerdings waren auch diejenigen, die es bis in die westalliierte Besatzungszone schafften, nicht vor Verfolgung geschützt. Sie mussten damit rechnen, von den Amerikanern oder den Briten an den jugoslawischen Staat ausgeliefert zu werden, was oft einem Todesurteil gleichkam. ${ }^{204}$ Andere, wie etwa Karl-Gustav Sauberzweig, der ehemalige Kommandeur der „Handschar“, begingen in westalliierter Kriegsgefangenschaft Suizid, um einer solchen Auslieferung zu entgehen. ${ }^{205}$ Aber auch diejenigen Soldaten, etwa der „Skanderbeg“ oder „Handschar“, die in ihre Heimatorte zurückkehrten, waren von Vergeltung betroffen. ${ }^{206}$

\section{Ebd.}

201 Vgl. „Zentralauskünfte für Rückgeführte“, 15.12.1944, NS 31/173, Bl. 1 und „Anwesenheitsliste von SS-Angehörigen aus dem Südost-Raum“, 29.12.1944, NS 31/173, Bl. 21.

202 Vgl. Calic, Geschichte Jugoslawiens, S. 172f. Vgl. Bernwald, Muslime, S. 327.

203 Bernwald beispielsweise hatte sich bereits in einen Kriegsgefangenenzug eingereiht, der Richtung Osten marschierte, entschied sich aber dann zur Flucht und schaffte es, mit zivilen Flüchtlingen von Braunau durch die Tschechoslowakei in die von Amerikanern kontrollierte Zone nach Cham in die Oberpfalz zu gelangen. Vgl. Bernwald, Muslime, S. 233-238.

204 Vgl. Bernwald, Muslime, S. 233.

205 Vgl. Reinhard Stumpf, Die Wehrmacht-Elite, Rang- und Herkunftsstruktur der deutschen Generale und Admirale 1933-1945, Boppard am Rhein: Harald Boldt 1982, S. 44.

206 Sie wurden teilweise mit Berufsverbot belegt. Vgl. Interview mit Sylë Kasumaj, Juni 2016. Andere wiederum wurden bspw. von Deva für ein letztes Aufgebot rekrutiert. Vgl. Malcolm, Kosovo, S. 312. 
Bereits seit dem 24. Mai 1944 war in den „Direktiven für Militärgerichte“ in den Artikeln 13 und 14 festgeschrieben worden, wer als „Feind des Volkes“ und wer als „Kriegsverbrecher“ zu gelten hatte. Diese mündeten schließlich am 25. August 1945 in das „Gesetz über Verbrechen an Volk und Staat“. ${ }^{207}$ Schon 1944 wurde eine jugoslawische Kommission eingerichtet, die Kriegsverbrechen untersuchen und ahnden sollte, die Državna Komisija za Utvrđivanje Zločina Okupatora i Njihovih Pomagača (DKUZOP), zu deutsch „Nationale Kommission zur Feststellung von Verbrechen durch die Besatzer und ihre Helfer“. ${ }^{208}$ Sie arbeitete einerseits mit der United Nations War Crimes Commission (UNWCC) zusammen, hatte aber andererseits auch spezifisch sozialistische Züge. Die Kommission hatte je nach Teilrepublik verschiedene Unterkommissionen; allein bei der bosnischen Kommission gingen in den zwei Jahren ihres Bestehens 66.632 Anzeigen ein, so Ferhadbegović. ${ }^{209}$ Portmann hingegen nennt eine Zahl von 66.420 „Kriegsverbrechern“, davon rund 17.000 Ausländer und 49.000 Einheimische für ganz Jugoslawien. ${ }^{210}$ Die Antifašističko Vijeće Narodnog Oslobođenja Jugoslavije (AVNOJ) eröffnete kurz nach dem Zweiten Weltkrieg, vertreten durch die DKUZOP, Verfahren gegen ehemalige Angehörige der „Handschar“ und der „Prinz Eugen“. Zur „Skanderbeg“ und „Kama“ finden sich hingegen in ex-jugoslawischen Archiven nur wenige Unterlagen. ${ }^{211}$

Seit dem 1. Dezember 1958 bis heute untersucht auch die „Zentrale Stelle der Landesjustizverwaltungen Ludwigsburg zur Aufklärung nationalsozialistischer Verbrechen“ die Gewalttaten der südosteuropäischen Waffen-SS Divisionen. ${ }^{212}$ Die Aufklärung von Kriegsverbrechen der Angehörigen der Divisionen „Prinz Eugen“, „Handschar“, „Skanderbeg“ und „Kama“ war jedoch oft nicht von dem gewünschten Erfolg gekrönt, wie verschiedene Einstellungsverfügungen von Ermittlungen gegen Angehörige dieser Divisionen zeigen. ${ }^{213}$

207 Vgl. Portmann, Communist Retaliation and Persecution, S. $53 \mathrm{f}$.

208 Vgl. ebd., S. $56 \mathrm{f}$.

209 Vgl. Ferhadbegović, Schuldig, S. 4.

210 Vgl. Portmann, Communist Retaliation and Persecution, S. 57.

211 Aufschlussreich ist in dieser Hinsicht der Bestand 110 (Državna Komisija za Utvrđivanje Zločina Okupatora i Njihovih Pomagača/DKUZOP) des Arhiv Jugoslvije. Darin finden sich die Akten ehemaliger Angehöriger der vier Waffen-SS-Divisionen oder lokalen Polizeieinheiten, die ebenfalls durch die SS rekrutiert wurden. Diese sind leider hinsichtlich der ehemaligen Divisionsangehörigen aus Kosovo und Sandžak unvollständig, oft findet sich nur noch der Name als Platzhalter, die Akte fehlt jedoch.

212 http://www.zentrale-stelle.de/pb/,Lde/Startseite (Stand: 4.4.2018).

213 So beispielsweise die Einstellungsverfügung der Staatsanwaltschaft Koblenz 9 Js 106/65 gegen Schwarz vom 31.9.1966. Vgl. Fall Schwarz, USHMM, BArchL, B 162/19145. Beschluss des Landgerichts Bad Kreuznach UR 2/65 - 213/66 (3 Js 3884/64) vom 22. Juli 1966, das Strafverfahren 
Bis heute beschäftigen die Massenexekutionen sowohl von Soldaten der Wehrmacht und Waffen-SS als auch vermeintlicher und echter Kollaborateure durch kommunistische Partisanen am Ende des Krieges in Südosteuropa die Öffentlichkeit: 2010 entdeckten von der Regierung finanzierte ForscherInnen in Slowenien ein riesiges Massengrab mit einer eineinhalb Meter dicken Schicht von Skeletten. In ihm und in weiteren Massengräbern in seiner unmittelbaren Umgebung sollen rund 100.000 Menschen, vor allem Soldaten der deutschen Wehrmacht und Waffen-SS, kurz nach dem Krieg verscharrt worden sein. Bis 2010 wurden bereits mehr als 600 solcher Massengräber entdeckt. ${ }^{214}$ Die meisten Massengräber finden sich in ehemaligen Panzergräben, aber auch Höhlen, Schluchten, Felsspalten oder Stollen. Sie werden bis heute nach und nach ausfindig gemacht und ausgehoben. ${ }^{215}$

Viele dieser Massengräber, etwa eines der größten bisher gefundenen in der Gegend um Brešice/Rann, waren dem HIAG-Archivar Wolfgang Vopersal bereits kurz nach dem Krieg bekannt. Er notiert in seinen Archivunterlagen, dass es sich bei den Erschossenen um deutsche Soldaten in Uniform handelte, ohne Rangabzeichen, die im Sommer 1945 dort erschossen und begraben worden seien. ${ }^{216}$ Die Ausgrabungen 2010 ergaben, dass neben Skeletten von Flüchtlingen und älteren „Volksdeutschen“, die aus der Gegend stammten, auch solche von Angehörigen der „Prinz Eugen“ dort verscharrt waren. ${ }^{217}$

Eine weitere Methode, sich der gefangenen deutschen Soldaten zu entledigen, war das Hinunterstürzen in Karstschluchten oder von Brücken. ${ }^{218}$ In einer Schlucht

gegen die Angehörigen der „Prinz Eugen“ Raff und Kubatschek „außer Verfolgung zu setzen“. Vgl. Fall Raff und Kubatschek, USHMM, BArchL, B 162/6252. Oder auch Einstellungsverfügung der Staatsanwaltschaft München I 116 Js 17/67 gegen Unbekannt vom 12. Juni 1972. Vgl. Anklage Staatsanwaltschaft München gegen Unbekannt, USHMM, BArchL, B 162/19144. Und auch im Falle Borkowsky („Handschar“) sah man nach anfänglichen Anstrengungen und der Notiz, dass die Aussage glaubwürdig erscheine, von einer weiteren Strafverfolgung ab; erwogen wurde hingegen, Borkowsky „wegen Vortäuschens einer Straftat bzw. falscher Anschuldigung“ strafrechtlich zu verfolgen. Vgl. Fall Günter Borkwosky USHMM, BArchL, B 162/20812, Bl. 299-301.

214 Karl Peter Schwarz, Eine eineinhalb Meter starke Schicht von Skeletten, in: http://www.faz. net/aktuell/politik/ausland/massengrab-in-slowenien-entdeckt-eine-eineinhalb-meter-starkeschicht-von-skeletten-11070164.html (Stand 6.2.2018).

215 Leider spielen solche Ausgrabungen oft auch Nationalisten in die Hände, welche durch die Verbrechen der Sozialistischen Föderativen Republik Jugoslawien eigene nationalistische Ziele legimitieren. Vgl. zur jener Instrumentalisierung auch Portmann, Communist Retaliation and Persecution, S. 47-49.

216 Notizen Vopersal, BarchF, Nachlass Vopersal, N756/168b.

217 Vgl. Karl Peter Schwarz, Eine eineinhalb Meter starke Schicht von Skeletten, in: http:// www.faz.net/aktuell/politik/ausland/massengrab-in-slowenien-entdeckt-eine-eineinhalbmeter-starke-schicht-von-skeletten-11070164.html (Stand 6.2.2018).

218 Calic, Geschichte Jugoslawiens, S. 173. Meiser, Ausgelöscht!, S. 113, 116. 
in Slovenska Bisrica/Windisch Feistriz sollen beispielsweise 10.000 Tote liegen. Die Schlucht wurde später gesprengt. In der Schlucht bei Eisenkappel, in Österreich nahe der slowenischen Grenze, sollen 250 Soldaten erschossen worden sein. ${ }^{219}$ Ein Kriegsgefangener erzählte 1947, dass bei Maribor/Marburg in Slowenien an Panzergräben 20-30.000 Soldaten erschossen wurden. Anderen Aussagen zufolge wurden Tausende von Waffen-SS- und Wehrmachtsoldaten bei Maribor in Felsenbunker einbetoniert und diese danach gesprengt. Auch bei Rifnik/Reichenegg wurden gefangene Soldaten in Bunker getrieben, die dann gesprengt wurden. Am 22. Mai 1945 wurden in Podsused, Kroatien, je 15 Mann, insgesamt 90, in Abständen von 10 Minuten an die Save gestellt und durch Genickschuss hingerichtet. Neunzig Mann einer Sanitätssammelstelle wurden bei Susegrad, $8 \mathrm{~km}$ westlich von Zagreb, von der Brückenwache der Partisanen zusammengetrieben, entkleidet, beraubt und nackt in die Save gejagt. ${ }^{220}$ So genannte „Sühne-“ und „Todesmärsche“ kosteten 1945 zahlreichen weiteren ehemaligen Soldaten und Zivilisten das Leben. ${ }^{221}$

Nach Calic sollen in „Säuberungsaktionen“ bei Kriegsende durch Tito-Partisanen rund 70.000 ehemalige Ustaša- und Četnik-Angehörige sowie Soldaten anderer militärischer Formationen hingerichtet worden, außerdem rund 60.000 in letzten Gefechten gefallen sein. ${ }^{222}$ Im Kosovo hielt die Kriegssituation auch nach dem offiziellen Kriegsende an: Dort hatten sich ehemalige Angehörige der „Skanderbeg“ und des „Balli Kombëtar“ in die Hügel und Wälder zurückgezogen und kämpften von da aus weiter. Tito sah sich schließlich gezwungen, in dieser Region zwischen Februar und Juni 1945 das Kriegsrecht zu verhängen. ${ }^{223}$ Die brutale Vergeltung an tatsächlichen oder vermeintlichen Kollaborateuren konnte zwar den letzten militärischen Widerstand brechen, allerdings stellten viele das neue System grundsätzlich in Frage und im Familienkreis lebten der „nationale“ Widerstand und seine Mythenbildung weiter. ${ }^{224}$

219 Vgl. Böhme, Geschichte der deutschen Kriegsgefangene I/1n, S. 109.

220 Vgl. ebd, S. $108 \mathrm{f}$.

221 Vgl. Portmann, Communist Retaliation and Persecution, S. 47. Vgl. auch. Böhme, Geschichte der deutschen Kriegsgefangenen, I/1, S. 115-117.

222 Vgl. Calic, Geschichte Jugoslawiens, S. 172f.

223 Vgl. Schmider, Kriegsschauplatz, S. 1054. Vgl. Malcolm, Kosovo, 1998, S. 317.

224 Vgl. Calic, Geschichte Jugoslawiens, S. 172f. 


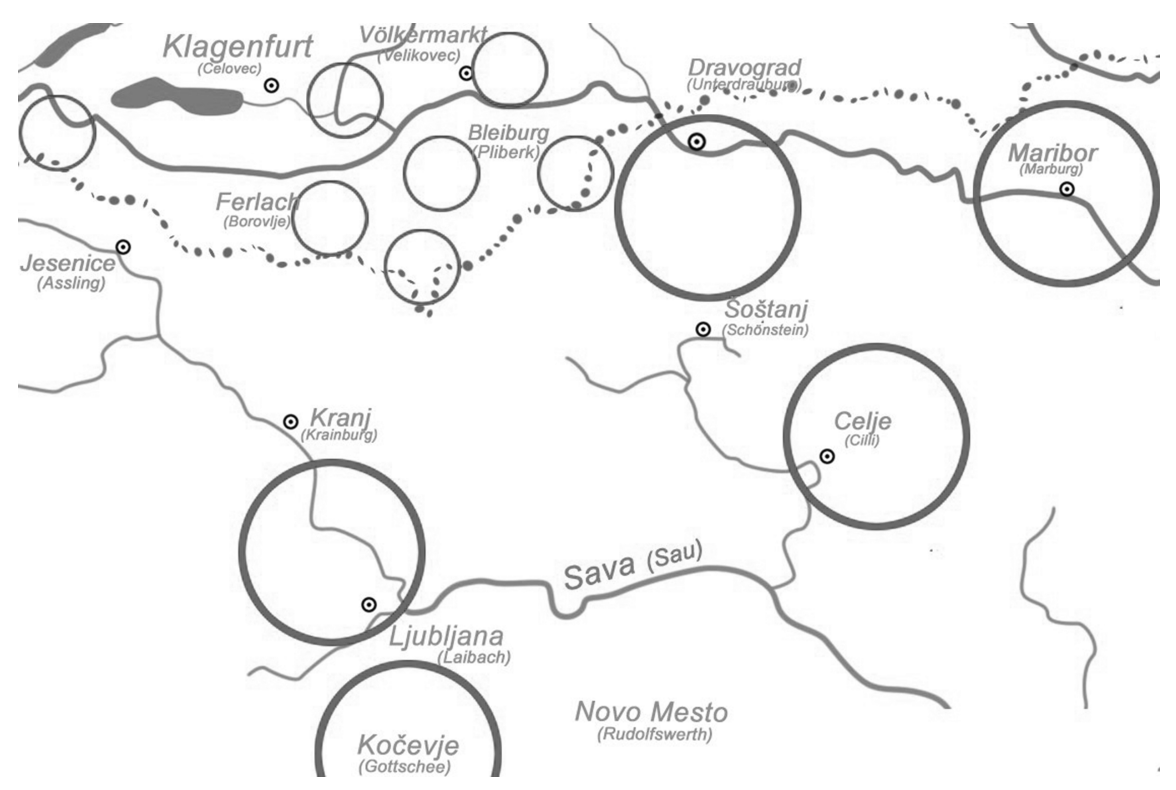

Abb. 45: Massengräber in Slowenien, sogenannte „Killingfields“. ${ }^{225}$

225 Florian T. Rulitz, Die Tragödie von Bleiburg und Viktring, Klagenfurt/Ljubljana/Wien: Hermagoras 2011. S. 211. https://www.meinbezirk.at/villach-land/lokales/was-war-das-massakervon-bleiburg-und-viktring-eine-rezension-des-buches-von-florian-thomas-rulitz-d242959.html (Stand: 6.2.2018). 